This item was submitted to Loughborough's Research Repository by the author.

Items in Figshare are protected by copyright, with all rights reserved, unless otherwise indicated.

\title{
A Markov switching unobserved component analysis of the CDX index term premium
}

PLEASE CITE THE PUBLISHED VERSION

http://dx.doi.org/10.1016/j.irfa.2016.01.020

PUBLISHER

(C) Elsevier

VERSION

AM (Accepted Manuscript)

\section{PUBLISHER STATEMENT}

This work is made available according to the conditions of the Creative Commons Attribution-NonCommercialNoDerivatives 4.0 International (CC BY-NC-ND 4.0) licence. Full details of this licence are available at: https://creativecommons.org/licenses/by-nc-nd/4.0/

\section{LICENCE}

CC BY-NC-ND 4.0

\section{REPOSITORY RECORD}

Calice, Giovanni, Christos loannidis, and RongHui Miao. 2019. "A Markov Switching Unobserved Component Analysis of the CDX Index Term Premium”. figshare. https://hdl.handle.net/2134/20697. 


\title{
A Markov Switching Unobserved Component Analysis of the CDX Index Term Premium
}

\begin{abstract}
Using a Markov switching unobserved component model we decompose the term premium of the North American CDX index into a permanent and a stationary component. We establish that the inversion of the CDX term premium is induced by sudden changes in the unobserved stationary component, which represents the evolution of the fundamentals underpinning the probability of default in the economy. We find evidence that the monetary policy response from the Fed during the crisis period was effective in reducing the volatility of the term premium. We also show that equity returns make a substantial contribution to the term premium over the entire sample period.
\end{abstract}

JEL Classification: G01, G15, G21, G24

Keywords: CDX index, Markov Switching, State-Space, Variance Decomposition, Term Premium 


\section{A Markov Switching Unobserved Component Analysis of the CDX}

\section{Index Term Premium}

\section{Introduction}

The sub-prime mortgage crisis, unveiled in July 2007, has caused remarkable losses in the credit markets. A large number of systemically important financial institutions had been forced to write off mortgages and related securities linked to credit derivatives instruments, like credit default swaps (CDSs) and collateralized debt obligations (CDOs). Great uncertainties filled almost every corner of the financial markets, which seriously interrupted its normal functioning (see Taylor and Williams (2009)). It has been argued (see, amongst the others, Longstaff (2010)) that the 2007/2008 sub-prime crisis was amplified through structured credit products-tranches trading. Consequently, if on the one hand, these instruments seem to have enriched the scope of investment strategies, on the other hand, their increased complexity depth have unduly induced instability in financial markets.

CDS indices are simply portfolios of single name default swaps, serving both as trading vehicles and as barometers of credit market conditions. Users of the most popular indices (the Dow Jones CDX North American investment grade (CDX-IG) and the iTraxx Europe investment grade (iTraxx-IG)) include those who want to hedge against credit defaults of pooled entities and those who want to speculate. These indices are responsible for the increased liquidity and popularity of tranching of credit risk. By buying protection on an index, an investor is protected against defaults in the underlying portfolio and makes quarterly premia payments to the protection seller. If there is a default, the protection seller pays par to the protection buyer. 
The term premium of the CDX index, which is measured as the difference between longer maturity CDX index series and shorter maturity, e.g. the difference between the CDX 10Year index and the CDX 5-Year index, can be viewed as representing the 5-year forward uncertainty regarding corporate default after the next 5 years. Accordingly, the CDX term premium can be interpreted as an early warning market indicator of improvement or deterioration in macroeconomic conditions 5 years hence. If an investor perceives the difference between the 5-year index spread and the 10-year spread too steep, in other words, that the implied probability of default ${ }^{1}$ between 5 and 10 years is higher than that implied from fundamentals, but he/she expects the slope to flatten, then this investor could buy 5-year protection and sell 10-year protection on the CDX index.

In this paper, we investigate the dynamic behavior of the CDX index term premium through time by using a Markov Switching Unobserved Component (MS-UC) model. In the econometric literature, several approaches have been proposed on how the univariate time series could be decomposed. A well-established methodology is the unobserved components approach, postulated in separate contributions by Harvey (1985), Watson (1986) and Clark (1987), respectively. It seems natural to consider an economic time series in terms of permanent and stationary components. The decomposition of a univariate time series into these two components is a primary tool for analyzing business cycles, with these two components often used as measurements of unobserved trend and cycle. Researchers also use unobserved component models to study the mean reversion in stock prices. Fama and French (1988) find a stationary mean reverting component in addition to a permanent component in the US stock price

\footnotetext{
${ }^{1}$ The implied probability of default here is a risk-neutral concept, i.e. it is jointly determined by actual default probability, the risk premium, the default risk premium and the liquidity risk premium. As a result, the level and changes of the CDX term premium can be driven by the forward uncertainty regarding corporate defaults (a physical concept) as well as the forward uncertainty regarding risk premium.
} 
dynamics. Poterba and Summers (1988) test for the existence of a stationary component although does not perform a formal decomposition of the stock prices in stationary and permanent components. Others like Lo and MacKinlay (1988) and Kim, Nelson and Startz (1991) use variance ratio tests to detect mean reversion in stock prices. Although the evidence of mean reversion in stock prices is mixed, as Summers (1986) argues that, statistical tests used in testing the random walk hypothesis have usually low power against the alternative of mean reversion.

In formulating an unobserved components model for econometric analysis, we depart from others who focus on the observable determinants of CDS indices. Alexander and Kaeck (2008) and Byström (2006), for example, relate the CDS/CDX spread to several observed variables (such as the slope of the yield curve, stock market return and stock market volatility), and analyze the significance of each observable variable in determining the CDS iTraxx Europe spread using single-equation regression.

Our interest in this paper, however, is to study how the factors themselves (not the factor loadings) drive the dynamics of the term premium. Since the CDX index measures the economywide default probabilities (the higher the index value, the higher the probability of default, e.g. firms included in the index), the macroeconomic conditions, which can be encompassed by those fundamental factors, will be closely related to the CDX index value and its term premium. To characterize the observed patterns of volatility jumps on the CDX index term premium, we allow on the innovation terms a regime switching process, following two distinct first-order Markov chain variables. Our paper has two main contributions. First, we present a readily implementable new approach to modeling CDS index dynamics, by conducting a regime dependent factor analysis of the evolution of the CDX index. Second, we provide insights into how the fundamental and volatility components of the CDX index are determined by daily observed 
monetary policy and stock market variables, before and after the onset of the global financial crisis.

The paper's main results are as follows. First, the inversion of the CDX term premium is induced by sudden changes in the stationary component, which represents the evolution of the fundamentals underpinning the probability of default in the economy. Equally notable is that our findings show that the non-stationary component, which represents increases in volatility, spikes quite dramatically around the occurrence of tail risk events (e.g. Bear Sterns bailout and Lehman Brothers bankruptcy).

Second, the empirical evidence strongly suggests that the direct impacts of monetary policy rates and the slope of the yield curve on the term premium of CDX index are time varying and depending on business cycle. Credit risk modeling that ignores this regime dependent feature would bias the pricing of credit contracts. Developments in both the first and second moments of the equity market have a lasting influence on both components, with more pronounced effects in volatile market conditions.

The paper is organized as follows. Section 2 reviews the related empirical literature. Section 3 discusses the possible economic determinants of the term premium and suggests its decomposition into two unobserved components allowing for regime switching. Section 4 presents and discusses the data used in the estimation. The results are reported in Section 5 and Section 5 concludes. 


\section{Related Literature}

The early literature on CDS is primarily limited to the pricing with a large strand revolving around the key determinants of these contracts. First, there is an extensive literature on the driving forces of CDS premia ranging from the model of Hull, Predescu and White (2004), Aunon-Nerin, Cossin, Hricko and Huang (2002), which examine the relationship between CDS premia and credit spreads, to more elaborate analysis by - amongst the others - Zhu (2006), Longstaff, Mithal and Neis (2005) and Blanco, Brennan and Marsh (2005) which include also bond and equity markets measures.

Much of the research on credit markets has focused on corporate bond spreads and single-name CDS premia. Despite a sizeable literature on credit risk, empirical studies on CDS that involve the modeling of the entire credit curve are uncommon. A major reason for this is that data on the CDS premia for a wide range of maturities have only recently become available. Consequently there is a paucity of empirical works regarding CDS indices, with studies focused mainly on the North America CDX investment grade index (CDX.NA.IG).

Blanco, Brennan and Marsh (2005) analyze the relationship between investment grade bonds and CDS, and explore the determinants of CDS premia. They find that the theoretical relationship linking credit spreads and CDS premia holds reasonably well for most of the investment grade reference entities. In addition, they report that increases in interest rates and equity prices reduce CDS premia whilst a steeper-sloping yield curve has the opposite effect.

The literature on CDS premia has been expanding considerably in the recent years. Berndt and Obreja (2010) show that European daily corporate CDS returns are significantly related to a factor which captures what the authors call "economic catastrophe risk". They seek 
to explain the residual common factor found by Collin-Dufresne et al. (2001) building a "catastrophic factor" as the difference between the spreads of tranches with different seniority in CDO products. Longstaff et al. (2011) examine sovereign CDS of 26 emerging countries at monthly frequency. They find that sovereign spreads are more associated with global factors (US stock, treasury, and high yield markets) than local factors (stock return, exchange rate, and foreign reserves). This evidence is further corroborated by a study of Fender et al. (2012) using daily data. They argue that the in the post-2007 period the impact of global factors even increased. Dieckmann and Plank (2012), using a panel of 18 European sovereign CDS (weekly frequency), find a significant positive association between stock market volatility and sovereign CDS spreads. They also show that the relative importance of a country's financial system before the euro debt crisis is the main reason for this association.

Due to data restrictions, studies modeling of the entire CDS term structure are rather rare. Byström (2005, 2006) and Alexander and Kaeck (2008) are the early studies on CDS indices. In a correlation study of a sample of European CDS iTraxx indices for different industrial sectors, Byström (2005) finds a tendency for iTraxx premia to narrow when stock prices rise, and vice versa. Furthermore, he finds that the stock market reacts quicker than the iTraxx market to firm-specific information and the stock price volatility is significantly and positively related to the volatility of CDS premia. Alexander and Kaeck (2008) use a Markov switching model to examine the determinants of the European CDS iTraxx index in two different regimes. Their results show that the CDS market is sensitive to stock returns under 'ordinary' market conditions but extremely sensitive to stock volatility during turbulent periods. One recent paper by Bhar, Colwell and Wang (2008), which is mostly related to our paper, decomposes three European CDS iTraxx indices premia into persistent and stationary components using 
Kalman filter. The authors investigate these dynamics for two different maturities (5 and 10 years) and find that the stationary component is affected largely by stock market volatility whereas the persistent component is more sensitive to illiquidity. However, their sample period does not include the recent sub-prime mortgage crisis. Therefore, the dynamic behavior of these two components during crisis times remains still unexplained.

Our work is also closely related to Pan and Singleton (2008) who attempt to estimate default risk using the entire credit curve of sovereign CDS premia for Korea, Mexico and Turkey. The authors find a strong comovement of the risk premiums across countries and with indicators of global risk appetite such as the VIX. Giesecke et al. (2012) use a regime-switching framework to examine the knock-on effects of US corporate defaults and US banking crises, in a sample going back to 1860 . They document that that banking crises have significant spillover effects to the macroeconomy, while corporate defaults do not.

This paper contributes to the rapidly growing literature on structured credit in its attempt to understand the evolution of the term premium of the CDS index market and its link to observed macroeconomic and financial information. In particular, we make two main contributions. First, we present a readily implementable new approach to modeling CDS index dynamics, by conducting a regime dependent factor analysis of the evolution of the CDX index. Second, we provide insights into how the fundamental and volatility components of the CDX index are determined by daily observed monetary policy and stock market variables, over a sample period surrounding the 2007-2009 global financial crisis.

The CDS term premium is generally positive, which corresponds to an upward sloping yield curve for bonds, but on specific occasions when immediate corporate default risk is perceived as substantial it can turn to negative values (i.e. as yield curve inversion). Our goal is to 
provide as benchmark for the dynamic behavior of the corporate credit risk, the term premium of the North American CDX index and analyze how it varied through the financial crisis period, when the volume and liquidity of the CDS market shrank dramatically. Therefore, we empirically determine the short-term drivers of the CDX term premium rather than provide a comprehensive treatment of asset pricing. We focus on the key elements in this analysis, namely the interaction of the permanent and transitory components with financial markets determinants, and maintain parsimony along other dimensions. In particular, we first decompose the term premium into two main component of distinct statistical nature: a stationary component and a permanent (random walk) component. Consequently, we posit that changes in a set of observable variables in the economy are highly informative about shifts in the direction of the two components, which, in turn, drives the behavior of the term premium. More specifically, changes in asset prices (interest rates, stocks, bonds, etc.) should be linked to time variation in the CDX term premium. Furthermore, information about changes in volatility regimes of each component may prove useful in determining the shape and direction of the entire CDS term premium.

Disaggregating the term premium in a way similar to the trend-cycle decomposition, enables us to understand the evolution of the CDX term premium in terms of predictable and unpredictable components and their links (in the subsequent VAR analysis) to: (i) the evolution of the US monetary policy (Federal funds policy rate), (ii) the slope of the yield curve (the difference between US Treasury bond rates) and (iii) other observed domestic financial variables (stock market returns: the S\&P 500 index, the implied volatility of the S\&P 500 index options: the VIX index). 


\section{Methodology}

The econometric methodology employed in this paper is based on the statistical approach developed initially by Nervole, Grether and Carvalho (1979) and developed further by Harvey (1989) and Harvey and Shephard (1993). The essential element of this methodology is to estimate a model, which considers the observed time series as being the sum of permanent and stationary components. These components capture the salient features of the series that may be unobserved and are useful in explaining and predicting its time evolution.

The UCM (unobserved components model) can be thought as a multiple regression model with time-varying coefficients. We employ such model because it allows for the interpretation of observed times series in terms of unobserved components which have an explicit interpretation and additionally permits conventional models of time series models to assign unequal weights to both near and far distant observations. In periods of when the economic and financial markets are in turmoil the neighboring observations may be more closely related with each other than observations belonging to another epoch. In adopting this modeling approach we are able to attach additional weight to recent observations, aiming at providing more robust estimates when applied to economic and financial time series, which span several epochs, than time series models that treat time series data "globally" and do not recognize explicitly such history.

The Kalman filter is employed as the most efficient means of updating the state as new information becomes available, in linear models. Although the latent variable model is an effective tool in decomposing macro/financial variables into a number of unobservable components, the usefulness of the model is however still limited if we are unable to link the components to a set of observable economic variables. To overcome this problem, one may 
model the unobserved components and observed variables together in a macro-finance setting (as suggested, for example, by Ang and Piazzesi (2003)). Our analytical approach here is instead as follows: we begin by filtering out the unobserved components and then in a second step, we empirically estimate the relationship between the unobserved components and a set of variables observed at the same frequency. The filtered two unobservable components are just two artificial components extracted from the term premium. Unobserved component models are traditionally used in business cycle analysis. The key feature of this class of models is the decomposition of an observed time series into unobserved trend and cycle components, while each extracted component is formulated as stochastic process evolving over time. This type of decomposition provides for a better understanding of the dynamic characteristics of the observed time series and the way these characteristics may change over time.

This provides a fairly robust statistically framework, which is akin to the cycle-trend decomposition commonly used in the business cycle analysis. Furthermore, our approach is primarily inspired by traditional inflation modelling frameworks. Whereas inflation (alike the CDS term premium) is generally regarded from the theoretical viewpoint as mean-reverting process, the empirical applications explicitly account for non-stationarity. Indeed, authors such as Stock and Watson (2007) have stressed the importance to distinguish between stationary and non-stationary components. Whereas the non-stationary component of inflation is now believed to be driven by structural factors that are subject to regime changes (e.g. monetary policy framework, credibility of inflation target), its stationary part can be reasonably linked to cyclical fluctuations of the economy in the original logic of the Phillips curve. 
Our aim is to test for the economically meaningful relationship between the unobserved components and a set of observed information that is available to both market participants and policy makers. Such link, if established, will add predictive ability to the model as the evolution of the components will be conditional on data and will enhance the model's analytical appeal.

At a conceptual level, the US Federal Fund Rate is the standard monetary policy tool available to the Fed to influence the short end of the yield curve and hence, in turn, affects investors' expectations on the movements of long-term interest rates. An increase in Federal Fund Rate signals the Fed's reaction against the risk of rising inflation in the near future and will aggravate the external financing position of companies that rely heavily on short-term financing. The impact of monetary policy on the term premium will be conditional on the state of the economy. Under "normal" conditions a tightening of monetary policy will indicate future inflationary pressures due to expanding demand. In this case, increases in the policy rate may be consistent with mitigating insolvency risks and thus with lower 5-year CDX premium. However in periods of crisis when expectations of future demand are gloomy, the same rate increases will enhance the probability of imminent default as the companies' abilities to secure funds at reasonable rates are reduced, resulting in widening 5-year CDX premium and a flattening of the CDX index term premium.

The slope of the yield curve reflects simply a forward expectation of how the short-term interest rate is expected to fluctuate over a long-term horizon and is largely driven by the marketwide expectations about the future path of monetary policy. Once more the impact of changes in the yield curve will depend upon the prevailing market conditions. Under stable market conditions increases in the long-rate imply future rises of the short rate. Such predicted evolution will impact positively on both the 5 and the 10-year CDX spread, rendering ambiguous its effect 
on the term premium. Under crisis condition the 'steepening' due to decreases in the short-rate curve will reduce the 5-year spread relatively to the 10 -year, increasing the term premium of the CDX index, as the reduction in the short-rate reduces the probability of imminent default.

The natural logarithm of the VIX index is a measure of forward uncertainty in the value of the firm's assets. Increasing uncertainty will hinder the ability of the markets to assess the true probability of default. It is not illogical to assume that an increase in the VIX is also associated with an increase in the 5-year uncertainty. As a result, risk adverse investors will demand "excessive" 5-year spread, reducing the term premium of the CDX index.

Additional features in our model are the interrelation between the stochastic elements of each component and the endogenous shift of their volatility between regimes. This feature enables us to capture the occasional and recurrent endogenous regime switches of volatilities in time series. To understand the rationale for assuming regime shifts in the two components' disturbance terms consider the evidence on the standard deviations for different time periods of the term premium presented in Table $1^{2}$.

Table 1: Mean and standard deviation of the CDX 5-year (CDX5Y), CDX 10-year (CDX10Y) and Term Premium (TP) for different sample periods

\begin{tabular}{l|rrr|rrr|rrr}
\hline \hline & \multicolumn{3}{|c|}{ Aug. 05, 2004 - Nov. 27, 2007 } & \multicolumn{2}{|c|}{ Nov.28, 2007 - Jul.23, 2009 } & \multicolumn{3}{c}{ Aug.05, 2004 - Jul.23, 2009 } \\
\cline { 2 - 10 } & CDX5Y & CDX10Y & \multicolumn{1}{c|}{ TP } & CDX5Y & CDX10Y & \multicolumn{1}{c}{ TP } & CDX5Y & CDX10Y & \multicolumn{1}{c}{ TP } \\
\hline Mean & 46.789 & 69.795 & 23.007 & 159.322 & 142.409 & -16.913 & 87.316 & 95.946 & 8.630 \\
Std. Dev. & 11.363 & 10.512 & 3.101 & 50.501 & 34.372 & 18.804 & 62.613 & 41.371 & 22.379 \\
\hline \hline
\end{tabular}

For the sample period between August 2004 and November 2007, the CDX term premium fluctuates narrowly around its mean at 23.007 with a modest standard deviation of 3.101. However, once interest rates began to rise and housing prices started to drop between 2006 and 2007 in many parts of the US, the refinancing of mortgages (especially the sub-prime

\footnotetext{
${ }^{2}$ Details of the data used in this paper are described in section 3.
} 
mortgages) became extremely difficult. Defaults and foreclosure on those mortgages increased dramatically, which brought the subprime mortgage industry to the edge of collapse, and hence generated considerable uncertainty in financial markets. The standard deviation of the CDX term premium between November 2007 and July 2009 jumps to 18.804, which is more than 6 times higher than the aforementioned period between August 2004 and November 2007. Concurrently, the mean of the term premium falls to -16.913 , suggesting that the CDX term premium might be experiencing a different regime in terms of both mean and volatility.

Traditionally, a sudden shift in the mean and volatility level of a time series would be modeled as a "structural break", in which this shift is due to some permanent changes in the economy's structure. Either can we pre-select the break points based on our prior or we let the data itself determine the break points endogenously (data-driven approach). However, the issue of identifying a structural break within a finite sample is a subtle one. A criticism of preselecting the break points is that this may lead to data-snooping. In addition, this method assumes these shifts in the economy's structure are deterministic and give no guidance on when they will appear again in the future. The data-driven approach of testing structural breaks also suffers a well-known criticism. A long time span of data is usually required to obtain consistent parameters, yet structural break tests require these parameters to be estimated by splitting the finite sample into even smaller subsamples. The search of structural breaks over small subsamples, as argued in Lo and MacKinlay (1990), can bias inference toward finding breaks where none exist, especially in a very persistent covariance stationary time series. This last criticism may be particularly relevant to our study here, in which our sample period ends on the July 23rd, 2009, only a short time after the astonishing decline in the credit market yet still in the big uncertainty about future economy's recovery. Given the data available to us, an alternative 
method to model the recent abrupt changes in the CDX term premium is to assume the changes are recurrent. By allowing for regime switches in volatility (and in mean) to take place endogenously, we do not explicitly set a switching threshold value but we allow for the data to decide endogenously when to switch to a different regime.

This regime-switching attribute in the unobserved components space allows us to generate probabilities that each component of the term premium experiences either high or low volatility regimes through time. Although it complicates the estimation procedures - since additional filters must be employed to make inference on the hidden Markov chain process allowing the two components to depend on different states of the economy provide us with an alternative approach to deal with the potential heteroskedastic variance in the daily CDX index series. The more conventional way of testing for financial time series heteroskedasticity is to consider ARCH-type volatility models, which allow constant unconditional volatility but timevarying conditional volatility. However, neglecting possible regime shifts in the unconditional variance, as shown in Lamoureux and Lastrapes (1990), would overestimate the persistence of the variance of a time series.

The remaining subsections present our stylized model of analysis. We first show how to construct the two components that drive the evolution of the CDX term premium. We outline the state space representation of the system and our extension of modeling Markov switching disturbance terms.

\subsection{Stationary and Random Walk Components in State Space Representation}


Following traditional business-cycle decomposition analysis, where the time series is decomposed into a trend and a cycle components, (see, Coopman and Ooms, 2011) we assume the CDX term premium consists of a mean reverting cyclical and a permanent trend components. We allow the cycle component to evolve over time in a mean-reversion fashion to characterise the notion that the fundamental driving forces of the spreads between the 10-year and the 5-year CDX indices should behave similarly to the term structure of yields curve.

We therefore postulate the following decomposition:

$Y_{t}($ term premium $)=X_{1, t}($ cyclical component $)+X_{2, t}($ permanent compenent $)$

The randomness of the premium is due solely to the presence of the two Brownian motions driving the two components.

Let $X_{1, t}$ represent the stationary component which drives the term premium, and assume that $X_{1, t}$ is an Ornstein-Uhlenbeck process, whose dynamic evolution can be described by the stochastic differential equation

$$
d X_{1, t}=k\left(\quad X_{1, t}\right) d t+\sim_{1} d Z_{1, t},
$$

where $\delta$ is the target equilibrium or mean value supported by fundamentals; $\tilde{\sigma}_{1}>0$ is the scale of volatility that the exogenous shocks can transmit to the dynamics of $X_{1, t} ; d Z_{1, t}$ is the standard Brownian motion with zero mean and unity variance. $k>0$ is the rate by which these shocks dissipate and the variable, $X_{1, t}$, reverts back to its mean. The Ornstein-Uhlenbeck process is an example of a Gaussian process that admits a stationary probability distribution and has a bounded variance.

Setting $f\left(X_{1, t}, t\right)=X_{1, t} e^{k t}$ and applying the Ito's Lemma to this function, this leads to

$$
d f\left(X_{1, t}, t\right)=k e^{k t} d t+\sim_{1} e^{k t} d Z_{1, t} .
$$


Integrating both sides of Equation (2), we obtain

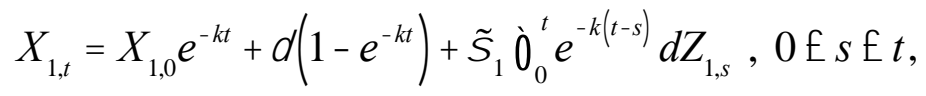

where $X_{1,0}$ is the initial value of the process and the first and the second moments are given by

$$
\begin{aligned}
E\left(X_{1, t}\right) & =X_{1,0} e^{k t}+\left(1 e^{k t}\right) \\
\operatorname{Var}\left(X_{1, t}\right) & =\frac{\sim_{2}\left(1 e^{2 k t}\right)}{2 k}
\end{aligned}
$$

The exact discrete time model correspond to Equation (1) is given by the following $\mathrm{AR}(1)$ process

$$
X_{1, t}=\delta\left(1-e^{-k \Delta t}\right)+e^{-k \Delta t} X_{1, t}+\sigma_{1} \Delta Z_{1, t},
$$

where $\Delta t=1 / 250$ is the sampling interval and $=\sim \sqrt{\frac{\left(1 e^{k t}\right)}{2 k}}$. For $k>0$ implies $e^{-k \Delta t}<1$ and hence stationarity, for $k \rightarrow 0$ or $\Delta t \rightarrow 0$ implies $e^{-k \Delta t} \rightarrow 1$ and the model converges to a unit root model.

Now, let $X_{2, t}$ be the second component that drives the term premium. The evolution of the term-premium should not be a monotonic function of time. In this case our chosen specification is a driftless Random Walk (RW) which allows for 'permanent shifts' due to the realizations of the Brownian $d Z_{2, t}$ but such movements are not compounded over time. Our chosen specification is shown in Equation (6)

$$
d X_{2, t}=\sigma_{2} d Z_{2, t}
$$

where $\sigma_{2}$ is the scaled volatility parameter and $d Z_{2, t}$ is the standard Brownian motion that can be assumed to be either dependent or independent of $d Z_{1, t}$. The discrete time version of Equation (6) yields 


$$
X_{2, t}=X_{2, t-1}+\sigma_{2} \Delta Z_{2, t} .
$$

Although a RW process, like the one described in Equation (7), has infinite unconditional mean and variance, the conditional mean and variance can be measured as

$$
\begin{aligned}
E_{t}\left(X_{2, t}\right) & =X_{2, t-1}, \\
\operatorname{Var}_{t}\left(X_{2, t}\right) & =\sigma_{2}^{2}
\end{aligned}
$$

where the conditional expectation of the process at current time $t$ depends only on the observation at previous time period.

Given the two unobserved components, constructed using Equations (1)-(7), we estimate the parameter space as given by the system in Equation (9), with the dynamics of the two components in a Bayesian updating manner, namely the Kalman filter algorithm based on a State Space system. State space representation is usually applied on dynamic time series models that involve unobserved variables (see, e.g., Engle and Watson (1981), Hamilton (1994), Kim and Nelson (1989)). In our modeling, the fact that the two driving forces of the CDX index term premium - stationary and random walk components - are assumed to be unobserved state variables leads to the justification of using the state space representation.

The state equation describes the dynamics of unobserved variables, which is shown below in Equation (9); the measurement equation that depicts the relation between measured variables and the unobserved state variables, as shown in Equation (10).

$$
\begin{aligned}
& {\left[\begin{array}{l}
X_{1, t} \\
X_{2, t}
\end{array}\right]=\left[\begin{array}{c}
\delta\left(1-e^{-k \Delta t}\right) \\
0
\end{array}\right]+\left[\begin{array}{cc}
e^{-k \Delta t} & 0 \\
0 & 1
\end{array}\right]\left[\begin{array}{l}
X_{1, t-1} \\
X_{2, t-1}
\end{array}\right]+\left[\begin{array}{l}
\varepsilon_{1, t} \\
\varepsilon_{2, t}
\end{array}\right],} \\
& {\left[\begin{array}{l}
\varepsilon_{1, t} \\
\varepsilon_{2, t}
\end{array}\right] \sim \mathrm{N}\left(\left[\begin{array}{l}
0 \\
0
\end{array}\right],\left[\begin{array}{cc}
\sigma_{1}^{2} & \sigma_{1} \sigma_{2} \rho_{12} \\
\sigma_{2} \sigma_{1} \rho_{21} & \sigma_{2}^{2}
\end{array}\right] \Delta t\right)}
\end{aligned}
$$




$$
Y_{t}=X_{1, t}+X_{2, t} \text {. }
$$

In Equation (9), the covariance terms $\sigma_{1} \sigma_{2} \rho_{12}$ and $\sigma_{2} \sigma_{1} \rho_{21}$ will be zero under the assumption of independence between the two disturbance terms (the correlation between the two disturbance terms $-\rho_{12}$ - is zero).

Equation (10) reduces further to give

$$
Y_{t}=H X_{t},
$$

where $Y_{t}$ is the term premium series and $H=\left[\begin{array}{ll}1 & 1\end{array}\right]$ represents the weights of two components in the term premium.

\subsection{State Space Model with Markov Switching Disturbances}

An additional feature of our model is to allow each component's disturbance term to depend on different states of the economy. In practice, we let the volatilities of the disturbance terms to switch between high and low volatility regimes. Formally, we assume that $\sigma_{1}^{2}$ and $\sigma_{2}^{2}$ in Equation (9) are driven by two discrete-valued, independent unobserved first-order Markov chain processes $S_{1, t}=\{0,1\}$ and $S_{2, t}=\{0,1\}$ given by

$$
\begin{aligned}
& \sigma_{1}^{2}=\left(1-S_{1, t}\right) \sigma_{1 H}^{2}+S_{1, t} \sigma_{1 L}^{2}, \sigma_{1 H}^{2}>\sigma_{1 L}^{2} \\
& \sigma_{2}^{2}=\left(1-S_{2, t}\right) \sigma_{2 H}^{2}+S_{2, t} \sigma_{2 L}^{2}, \sigma_{2 H}^{2}>\sigma_{2 L}^{2}
\end{aligned} .
$$

When both $S_{1, t}$ and $S_{2, t}$ are zeros, the two components will be in the high volatility state as $\sigma_{1}^{2}=\sigma_{1 H}^{2}$ and $\sigma_{2}^{2}=\sigma_{2 H}^{2}$; similarly if both $S_{1, t}$ and $S_{2, t}$ equal 1 , the two components will be in the low volatility state since $\sigma_{1}^{2}=\sigma_{1 L}^{2}$ and $\sigma_{2}^{2}=\sigma_{2 L}^{2}$. The two remaining scenarios then categorize situations where the first component is in the high volatility state while the second is in the low ( $\left.S_{1, t}=0, S_{2, t}=1\right)$ and where the first component is in the low volatility state while the second is in 
the high $\left(S_{1, t}=1, S_{2, t}=0\right)$. The likelihood for the process to remain at the previous value or change to the alternative depends on the transition probabilities from one state to the other, which are shown below as

$$
\begin{aligned}
& p_{1,00}=\operatorname{Pr}\left[S_{1, t}=0 \mid S_{1, t-1}=0\right] \\
& p_{1,11}=\operatorname{Pr}\left[S_{1, t}=1 \mid S_{1, t-1}=1\right] \\
& p_{2,00}=\operatorname{Pr}\left[S_{2, t}=0 \mid S_{2, t-1}=0\right] \\
& p_{2,11}=\operatorname{Pr}\left[S_{2, t}=1 \mid S_{2, t-1}=1\right]
\end{aligned} .
$$

To estimate the transition probabilities as shown above requires the choice of the appropriate functional forms of the probability functions that govern the Markov chain variables. Since the transition probabilities have to be bounded within $[0,1]$ the usual choice is the adoption of the logistic transformation on the probability terms as:

$$
\begin{aligned}
& p_{1,00}=\operatorname{Pr}\left[S_{1, t}=0 \mid S_{1, t-1}=0\right]=\frac{\exp \left(d_{1,0}\right)}{1+\exp \left(d_{1,0}\right)} \\
& p_{1,01}=1-p_{1,00} \\
& p_{1,11}=\operatorname{Pr}\left[S_{1, t}=1 \mid S_{1, t-1}=1\right]=\frac{\exp \left(d_{1,1}\right)}{1+\exp \left(d_{1,1}\right)} \\
& p_{1,10}=1-p_{1,11} \\
& p_{2,00}=\operatorname{Pr}\left[S_{2, t}=0 \mid S_{2, t-1}=0\right]=\frac{\exp \left(d_{2,0}\right)}{1+\exp \left(d_{2,0}\right)} \\
& p_{2,01}=1-p_{2,00} \\
& p_{2,11}=\operatorname{Pr}\left[S_{2, t}=1 \mid S_{2, t-1}=1\right]=\frac{\exp \left(d_{2,1}\right)}{1+\exp \left(d_{2,1}\right)} \\
& p_{2,10}=1-p_{2,11}
\end{aligned}
$$

where $d_{1,0}, d_{1,1}, d_{2,0}$ and $d_{2,1}$ are unconstrained parameters. The accompanying Appendix presents a detailed account of the estimation procedure used in this paper. 


\section{Data}

CDS contracts are by nature over-the-counter. As a result, the availability and quality of the data are not as dependable as those of exchange-based transactions. Mainly large investment banks collect the data for CDS. These banks record only their own entering transactions. Although professional data vendors are the primary source of CDS research data the data suffer the following pitfalls: (1) as in Zhu (2006), data prior to 1999 are very limited; (2) the frequency of CDS transaction data is low, therefore, the usual instantaneous lead-lag analysis which use much higher frequency data may not be robust; (3) CDS prices are usually obtained as "quoted" prices which may not reflect the actual information contained in trading prices; (4) CDS data are truncated in the way that the majority contracts have a maturity of 5 years with nominal amount of $\$ 5$ million or $\$ 10$ million; (5) CDS data are usually unevenly spaced with many spurious observations in time series ${ }^{3}$.

To circumvent the limitations mentioned above, we restrict our sample of analysis to the CDS tranche index market, specifically to the North American CDX investment-grade indices. In these indices, all 125 single-name credits have equal weights in the portfolio. The Dow Jones CDX IG five-year index is a basket of CDSs on 125 names for the U.S. investment-grade market. Each reference entity has a weight of $0.8 \%$. The main index comprises reference entities from five sectors (sub-indices): Consumer, Energy, Financials, Industrials and Telecom, Media and Technology (TMT). We use a representative dataset of daily CDS prices for the North American CDX tranche index and focus our analysis on the most liquid segments of the CDX index market, which are the 5-year and 10-year maturities. The analysis is based on daily data spanning from 2004 to 2009. The main source of CDX data is Markit.

\footnotetext{
${ }^{3}$ An in-depth discussion of CDS data quality can be found in Blanco, et al. (2005).
} 
In our sample period (August 5, 2004 to July 23, 2009), as shown in Table 2 and Figure 1, the average premium is 87.3161 basis points for the CDX 5-year index and 95.9463 for the CDX 10-year index. The CDX 5-year index reaches its maximum spread (283 basis points) on September 16, 2008, which is the day after the announcement of Lehman Brothers default. Similarly, the CDX 10-year index reaches its maximum premium (251 basis points) on the same day, as it is reflected in the negative slope of the credit curve. Not only the volatility of the CDS indices increased dramatically as of July 2007, but also the levels of these indices started to rise significantly at the onset of the crisis. This unprecedented financial turmoil directly raised investors' expectations on imminent future defaults of firms' debts, especially of those financial firms heavily exposed to sub-prime-mortgage lending. From the second panel of Figure 1, we can see that the term premium of the CDX 10-year - 5-year index becomes negative at the start of 2008, suggesting an increase of investors' concerns over short-term default risk. Nevertheless, market sentiment remains unchanged over long-term horizons.

Daily Federal Fund Rates $(F F R)$ are obtained from the St. Louis FRED database. Daily slope of the yield curve (SLOPE101), calculated using 10-year and 1-year U.S. Treasury bond yields, are from Thomson Reuters@ Datastream. S\&P 500 index daily return (SP500RTN) observations are obtained from Thomson Reuters@ Datastream. VIX index (VIX) data are from the Chicago Options Mercantile Exchange (CBOE). The descriptive statistics of monetary policy and equity market condition variables are also presented in Table 2 and

Figure 2 plots their evolution over the sample period. 
Table 2: Descriptive statistics of the data series

\begin{tabular}{l|c|c|c|c|c|c|c}
\hline \hline & CDX5Y & CDX10Y & TP & FFR & SLOPE101 & SP500RTN & VIX \\
\hline Mean & 87.316 & 95.946 & 8.630 & 3.289 & 1.268 & -0.0001 & 21.236 \\
\hline Median & 53.000 & 77.000 & 22.000 & 3.620 & 1.045 & 0.0007 & 15.630 \\
\hline Maximum & 283.371 & 251.363 & 33.000 & 5.410 & 4.010 & 0.104 & 80.860 \\
\hline Minimum & 29.000 & 54.000 & -53.333 & 0.080 & -0.780 & -0.095 & 9.890 \\
\hline Std. Dev. & 62.613 & 41.371 & 22.379 & 1.811 & 1.233 & 0.016 & 12.877 \\
\hline Skewness & $1.197 * * *$ & $1.191 * * *$ & $-1.332 * * *$ & $-0.492 * * *$ & $0.278 * *$ & $-0.253 * *$ & $1.898 * * *$ \\
\hline Kurtosis & $3.202 * * *$ & $3.417 * * *$ & $3.607 * *$ & $1.885 * * *$ & $1.912 * * *$ & $12.357 * * *$ & $6.543 * * *$ \\
\hline Jarque-Bera & 281.280 & 284.875 & 363.461 & 105.915 & 71.541 & 4277.339 & 1312.913 \\
\hline 0.000$]$ & {$[0.000]$} & {$[0.000]$} & {$[0.000]$} & {$[0.000]$} & {$[0.000]$} & {$[0.000]$} \\
\hline Observations & 1169 & 1169 & 1169 & 1169 & 1169 & 1169 & 1169 \\
\hline \hline
\end{tabular}

Note: Jarque-Bera test is the test for the null of normality, p-values are reported in square brackets.

$(*, * *, * * *$, indicates significantly different from the values consistent with normality at $10 \%, 5 \%$ and $1 \%$ levels )

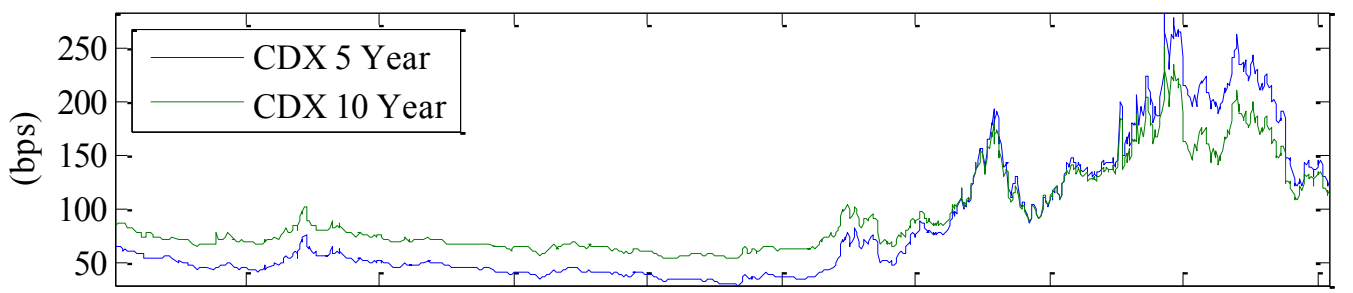

18/02/05 06/09/05 25/03/06 11/10/06 29/04/07 15/11/07 02/06/08 19/12/08 07/07/09

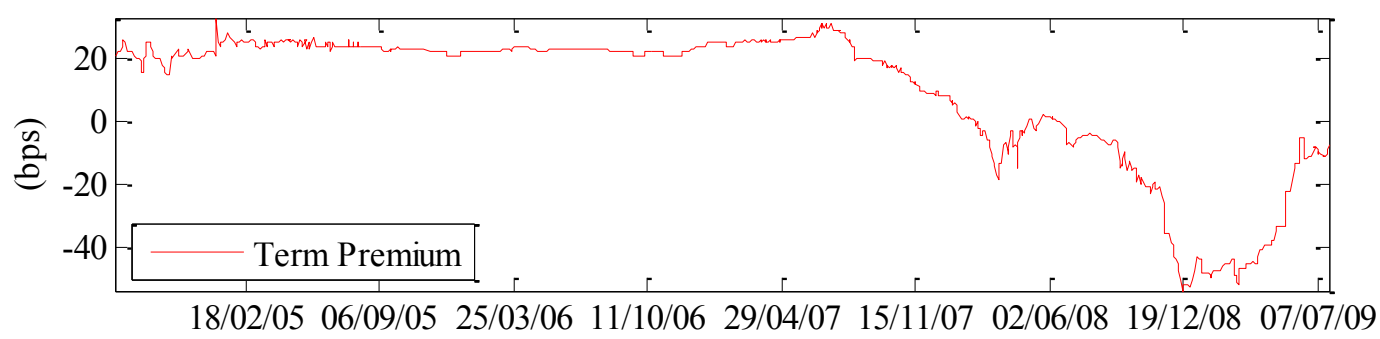

Figure 1: CDX-5 year, CDX-10 Year and CDX term premium 

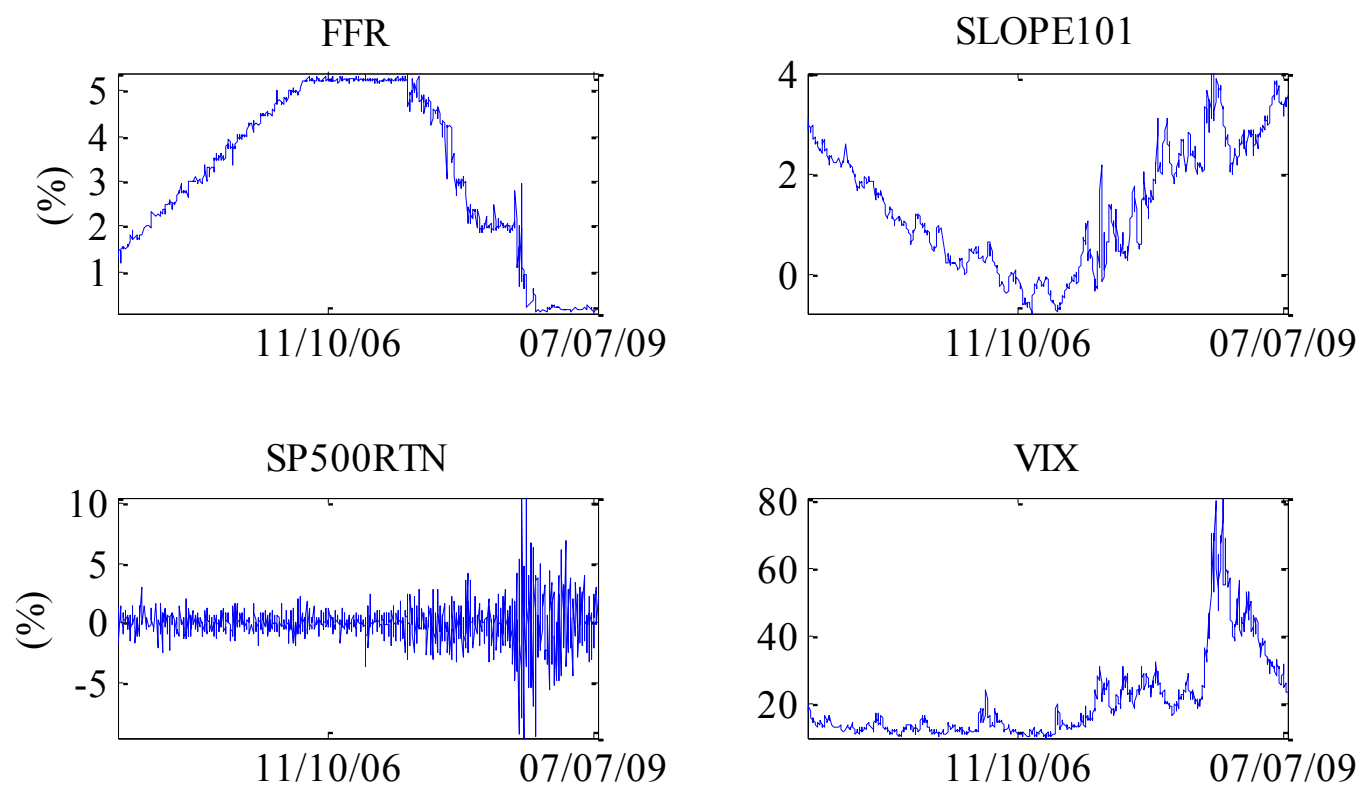

Figure 2: Actual plots of: FFR, SLOPE101, SP500RTN and VIX

\section{Empirical Results}

Using the methodology described in section 2, we estimate a series of nested Markovswitching unobserved component models, followed by a battery of tests on model specification to determine the preferred model that will be used in the empirical analysis.

\subsection{Model selection tests}

It is well known that for Markov-switching models the standard likelihood ratio test of the null hypothesis of linearity does not have the usual $\chi^{2}$ distribution. The reason is that there are nuisance parameters, which cannot be identified under the null hypothesis. As a result, the scores evaluated at the null hypothesis are identically zero. Hansen (1992) and Garcia (1998) introduce alternative tests of the linearity against regime switching. In this paper, we use Hansen 
(1992)'s procedure, which provides an upper bound of the $p$-value for linearity, to determine the significance of improvement of allowing Markov-switching disturbance terms in the two components. In addition, we also consider more conventional ways of selecting models based on the Akaike Information Criterion (AIC) and Schwarz Bayesian Information Criterion (BIC). Finally, we confirm our model selection results by running a series of residual diagnostic tests to see if the selected model captures both the serial correlation and heterskedasticity in the data series, resulting in white noise residuals.

To implement Hansen (1992)'s procedure, we evaluate the constrained likelihood under the null hypothesis over a grid of values for the nuisance parameters. We define the restricted model under null hypothesis as no regime switching of the two components' Equations 9-10, with $\rho_{12}=\rho_{21}=0$, and the alternative model of Markov-switching depicted in Equations (9)(14). In this specification the nuisance parameters are the following: $\left\{\sigma_{1 H}, \sigma_{2 H}, p_{1,00}, p_{1,11}, p_{2,00}, p_{2,11}\right\}$. The grids ${ }^{4}$ that we used for $\sigma_{1 H}$ and $\sigma_{2 H}$ are $[1,2.5]$ and $[5,10.5]$, respectively, each in increment step of 0.5 . The grids for $\left\{p_{1,00}, p_{2,00}\right\}$ varies from 0.7 to 0.9 in increment step of 0.05 and for $\left\{p_{1,11}, p_{2,11}\right\}$ from 0.8 to 0.9 in increment step of 0.05 . The Hansen test applied as described above yields a conservative $p$-value of 0.001 , which clearly indicate strong rejection of linearity in favor of Markov-switching model.

We test whether a model that permits correlated disturbance terms performs better than a model restricting correlations between the disturbances of the two components, and we present our results in Table 3 and Table 4. While AIC and BIC select correlated models, the likelihood

\footnotetext{
${ }^{4}$ Following Hansen (1992) "A trade off arises as a more extensive gird search requires more computation, but reduces the arbitrariness associated with the choice of grid, and may increase the power of test." The grid size is chosen as an outcome of balancing the computation effort and accuracy of the power of test needed
} 
ratio tests show Models 1 and 2 have better fit than Models 5 and 6, respectively. However, the improvement in likelihood value when allowing correlations and all parameters to switch between regimes (Model 8) is overwhelming. Meanwhile, we also report the likelihood ratio tests within each nested group in Table 5, from which we establish that the most flexible model (Model 8) performs best.

We corroborate this result with the residual diagnostic tests in Table 6, where we test the statistical behavior of the residuals from all the models (summation of the disturbance terms of the two components) under the null hypothesis of white noise. We report two Ljung-Box Q statistics for each model: one is the autocorrelation $Q$ statistics based on the standardized residuals up to 20 lags; the other one is the $\mathrm{ARCH}$ effect $\mathrm{Q}$ statistics based on the squared standardized residuals up to 20 lags. From Table 6, the Q statistics suggest Model 8 as the best performing model, as the null of white noise is not rejected at any lag length.

Table 3: Model selection results

\begin{tabular}{|c|c|c|c|c|}
\hline Model Specifications & No. of parameters & AIC & $\mathrm{BIC}$ & $\ln L$ \\
\hline $\begin{array}{l}\text { Model 0: } \rho_{12}=\rho_{21}=0 \\
\text { (single regime) }\end{array}$ & 4 & 3.135 & 3.152 & -1798.390 \\
\hline Model 1: $\rho_{12}=\rho_{21}=0$ & 10 & 2.800 & 2.844 & -1600.010 \\
\hline $\begin{array}{l}\text { Model 2: } \rho_{12}=\rho_{21}=0 \\
(k \text { is regime dependent })\end{array}$ & 11 & 2.777 & 2.826 & -1585.916 \\
\hline $\begin{array}{l}\text { Model 3: } \rho_{12}=\rho_{21}=0 \\
(\delta \text { is regime dependent })\end{array}$ & 11 & 2.763 & 2.811 & -1577.435 \\
\hline $\begin{array}{l}\text { Model 4: } \rho_{12}=\rho_{21}=0 \\
\text { (both } k \text { and } \delta \text { are regime dependent) }\end{array}$ & 12 & 2.690 & 2.743 & -1534.727 \\
\hline Model 5: $\rho_{12}=\rho_{21} \neq 0$ & 14 & 2.801 & 2.863 & -1596.695 \\
\hline $\begin{array}{l}\text { Model 6: } \rho_{12}=\rho_{21} \neq 0 \\
(k \text { is regime dependent })\end{array}$ & 15 & 2.782 & 2.848 & -1584.757 \\
\hline $\begin{array}{l}\text { Model 7: } \rho_{12}=\rho_{21} \neq 0 \\
(\delta \text { is regime dependent })\end{array}$ & 15 & 2.762 & 2.828 & -1573.281 \\
\hline $\begin{array}{l}\text { Model 8: } \rho_{12}=\rho_{21} \neq 0 \\
\text { (both } k \text { and } \delta \text { are regime dependent) }\end{array}$ & 16 & 2.671 & 2.741 & -1519.815 \\
\hline
\end{tabular}


Note: Model 0 refers to system of Equations 9-10 assuming $\rho_{12}=\rho_{21}=0$. Model 1 builds on Model 0 with Markov-switching variances defined in Equations 13-16; Model 2 builds on Model 1 but allow $k$ to switch regimes; Model 3 builds on Model 1 but allow $\delta$ to switch regimes; Model 4 builds on Model 1 but allow both $k$ and $\delta$ to switch regimes; Models 5-8 differ from 1-4 for allowing correlations between the two components' disturbance terms. $\ln L$ denotes the natural logarithm of likelihood value. AIC denotes the Akaike Information Criterion and BIC denotes the Schwarz Bayesian Information Criterion. A smaller statistic of AIC or BIC corresponds to smaller estimated Kullback-Leibler distance from the true model.

Table 4: Likelihood ratio tests on constraint $\rho_{12}=\rho_{21}=0$

\begin{tabular}{l|c|c}
\hline \hline Constraint: $\rho_{12}=\rho_{21}=0$ & Likelihood ratio & p-value \\
\hline Model 1 to Model 5 & 6.629 & 0.157 \\
\hline Model 2 to Model 6 & 2.318 & 0.678 \\
\hline Model 3 to Model 7 & 8.309 & 0.081 \\
\hline Model 4 to Model 8 & 29.825 & $5.313 \mathrm{E}-06$ \\
\hline \hline
\end{tabular}

Table 5: Likelihood ratio tests within groups

\begin{tabular}{l|c|c}
\hline Constraints & Likelihood ratio & p-value \\
\hline $\begin{array}{l}\text { Model } 1 \text { to Model } 2 \\
(k \text { is regime dependent) }\end{array}$ & 28.187 & 0.000 \\
\hline $\begin{array}{l}\text { Model } 1 \text { to Model } 3 \\
(\delta \text { is regime dependent) }\end{array}$ & 45.149 & $1.826 \mathrm{E}-11$ \\
\hline $\begin{array}{l}\text { Model } 1 \text { to Model } 4 \\
\text { (both } k \text { and } \delta \text { are regime dependent) }\end{array}$ & 130.565 & $4.447 \mathrm{E}-29$ \\
\hline \multicolumn{1}{c}{ Group of models apply $\rho_{12}=\rho_{21} \neq 0$} & \\
\hline $\begin{array}{l}\text { Model } 5 \text { to Model } 6 \\
(k \text { is regime dependent) }\end{array}$ & 23.876 & $1.027 \mathrm{E}-06$ \\
\hline $\begin{array}{l}\text { Model } 5 \text { to Model } 7 \\
(\delta \text { is regime dependent })\end{array}$ & 46.829 & $7.746 \mathrm{E}-12$ \\
\hline $\begin{array}{l}\text { Model } 5 \text { to Model } 8 \\
\text { (both } k \text { and } \delta \text { are regime dependent) }\end{array}$ & 153.761 & $4.085 \mathrm{E}-34$ \\
\hline
\end{tabular}

Table 6: Residual diagnostic tests

\begin{tabular}{|c|c|c|c|c|c|c|c|c|}
\hline \multirow[b]{2}{*}{ Lags } & \multicolumn{2}{|c|}{ Autocorrelation } & \multicolumn{2}{|c|}{$\mathrm{ARCH}$} & \multicolumn{2}{|c|}{ Autocorrelation } & \multicolumn{2}{|c|}{$\mathrm{ARCH}$} \\
\hline & Q-stats & p-value & Q-stats & $\mathrm{p}$-value & Q-stats & p-value & Q-stats & p-value \\
\hline & \multicolumn{4}{|c|}{ Model 0} & & & & \\
\hline 1 & 3.3651 & 0.0666 & 55.4375 & $1.00 \mathrm{E}-13$ & & & & \\
\hline
\end{tabular}




\begin{tabular}{|c|c|c|c|c|c|c|c|c|}
\hline 5 & 6.4061 & 0.2687 & 56.5142 & $6.37 \mathrm{E}-11$ & & & & \\
\hline 10 & 21.4859 & 0.0179 & 84.9913 & $5.00 \mathrm{E}-14$ & & & & \\
\hline \multirow[t]{2}{*}{20} & 51.2066 & 0.0001 & 128.0163 & $0.00 \mathrm{E}+00$ & & & & \\
\hline & \multicolumn{4}{|c|}{ Model 1} & \multicolumn{4}{|c|}{ Model 5} \\
\hline 1 & 5.8659 & 0.0154 & 12.4945 & 0.0004 & 0.002 & 0.9643 & 1.4605 & 0.2268 \\
\hline 5 & 38.7978 & 0 & 77.4846 & 0 & 21.916 & 0.0005 & 12.6867 & 0.0265 \\
\hline 10 & 46.7586 & 0 & 98.3647 & 0 & 39.9475 & 0 & 21.0755 & 0.0206 \\
\hline \multirow[t]{2}{*}{20} & 127.264 & 0 & 157.386 & 0 & 91.3123 & 0 & 42.9094 & 0.0021 \\
\hline & \multicolumn{4}{|c|}{ Model 2} & \multicolumn{4}{|c|}{ Model 6} \\
\hline 1 & 10.665 & 0.0011 & 2.0368 & 0.1535 & 12.7731 & $3.52 \mathrm{E}-04$ & 2.2811 & 0.131 \\
\hline 5 & 64.4022 & 0 & 6.0608 & 0.3003 & 69.3635 & $0.00 \mathrm{E}+00$ & 5.6359 & 0.3433 \\
\hline 10 & 129.4365 & 0 & 38.6211 & 0 & 140.9098 & $0.00 \mathrm{E}+00$ & 48.6666 & 0 \\
\hline \multirow[t]{2}{*}{20} & 244.9473 & 0 & 59.528 & 0 & 256.8626 & $0.00 \mathrm{E}+00$ & 67.5147 & 0 \\
\hline & \multicolumn{4}{|c|}{ Model 3} & \multicolumn{4}{|c|}{ Model 7} \\
\hline 1 & 34.5333 & 4.19E-09 & 0.3524 & 0.5528 & 14.6746 & $1.28 \mathrm{E}-04$ & 0.0017 & 0.9673 \\
\hline 5 & 73.5529 & $0.00 \mathrm{E}+00$ & 13.7145 & 0.0175 & 22.747 & $3.77 \mathrm{E}-04$ & 0.0029 & 1 \\
\hline 10 & 94.9219 & $0.00 \mathrm{E}+00$ & 37.0741 & 0.0001 & 50.5479 & $2.00 \mathrm{E}-07$ & 1.4622 & 0.999 \\
\hline \multirow[t]{2}{*}{20} & 114.7697 & $0.00 \mathrm{E}+00$ & 97.5292 & 0 & 76.9609 & $0.00 \mathrm{E}+00$ & 1.4862 & 1 \\
\hline & \multicolumn{4}{|c|}{ Model 4} & \multicolumn{4}{|c|}{ Model 8} \\
\hline 1 & 9.6918 & 0.0019 & 0.0337 & 0.8544 & 1.0875 & 0.297 & 0.0044 & 0.9468 \\
\hline 5 & 19.6283 & 0.0015 & 1.3234 & 0.9325 & 4.0601 & 0.5408 & 0.0107 & 1 \\
\hline 10 & 37.2164 & 0.0001 & 13.1973 & 0.2128 & 9.7284 & 0.4646 & 0.0267 & 1 \\
\hline 20 & 56.5368 & 0 & 16.2277 & 0.7024 & 22.5042 & 0.3138 & 0.1733 & 1 \\
\hline
\end{tabular}

\subsection{Estimates of the Markov-switching unobserved component model}

Table 7 reports the maximum likelihood estimates of Model 8, the most flexible and best performing model suggested by the model selection procedures considered above. The first 
noticeable result is the two regime dependent long-term equilibria of the stationary component: 8.4516 and in the low volatility regime and -0.5633 in the high regime. As can be seen, during the period of 'calm' (part of the Great Moderation epoch, from August 05, 2004 to December 31 , 2007), the slope along the credit curve is positive since the term premium is the compensation for default risk in 5 years-time as no crisis was envisaged. However, since the outbreak of the crisis (August 2007), severe strains in financial markets, banks' assets writedowns and diminishing liquidity in funding markets raised the level of uncertainty about corporate default risk. The inversion of the credit curve, as embedded in a negative CDX index term premium, captures vividly this deteriorating outlook. It is evident from Figures 4 and 5 that the two components are trends that stay in a regime quite persistently. Even from the plot of the term premium series, it is clear that the volatility of the series jumped to a level which was dramatically higher compared to its historic level during the financial crisis period, and stayed there for considerable time. It is not surprising that the estimation of the probability of staying in this regime is high given the infrequent changes of regimes for both components.

Table 7: Estimation results of Model 8

\begin{tabular}{l|c|c}
\hline \hline Parameters & Estimate & Std. Error \\
\hline$\delta_{L}$ & 8.45161 & 0.19273 \\
\hline$\delta_{H}$ & -0.56331 & 0.22730 \\
\hline$k_{L}$ & 465.078 & 30.5714 \\
\hline$k_{H}$ & 23.9443 & 3.79152 \\
\hline$\sigma_{1, L}$ & 0.00656 & 0.01754 \\
\hline$\sigma_{1, H}$ & 7.23834 & 0.74797 \\
\hline$\sigma_{2, L}$ & 0.00071 & 0.00672 \\
\hline$\sigma_{2, H}$ & 4.11551 & 0.23609 \\
\hline$\rho_{1 L, 2 L}$ & 0.88234 & 2.69776 \\
\hline$\rho_{1 H, 2 L}$ & -0.88688 & 23.16079 \\
\hline \hline
\end{tabular}




\begin{tabular}{l|l|l}
\hline \hline$\rho_{1 L, 2 H}$ & -0.62831 & 4.08741 \\
\hline$\rho_{1 H, 2 H}$ & -0.72941 & 0.21734 \\
\hline$p_{1, L L}\left(p_{1,00}\right)$ & 0.99561 & 0.00149 \\
\hline$p_{1, H H}\left(p_{1,11}\right)$ & 0.99999 & $1.68 \mathrm{E}-06$ \\
\hline$p_{2, L L}\left(p_{2,00}\right)$ & 0.96427 & 0.00110 \\
\hline$p_{2, H H}\left(p_{2,11}\right)$ & 0.97346 & 0.00068 \\
\hline $\ln L$ & & \\
\hline $\operatorname{lin}$
\end{tabular}

Note: Subscript $\mathrm{L}$ denotes Low volatility regime and $\mathrm{H}$ denotes High volatility regime.

The second remarkable result is the regime dependent mean reverting speed for the stationary component. During non-crisis periods, asset prices are less likely to stay high or low from period-to-period but mean-revert quickly to their long-term equilibrium values. In other words, mean reverting assets prices imply a low probability of ending up in the tail of the distribution. Our estimate of the measure of mean reverting speed $(k)$ is 465.07 in a low volatility regime, which translates to a first-order autocorrelation of 0.1556 . The speed in the high volatility regime, on the other hand, falls to 23.94 or 0.9087 , which suggests a very persistent behavior of the stationary component in the high volatility regime.

Next, we examine the volatilities of stationary and RW components in each regime. In terms of stationary shocks, the estimated volatility in the low volatility regime is statistically insignificant. This is primarily due to the very high mean reverting speed in this regime. It is clearly shown in Figure 3 that the stationary component's variation in low volatility regime is closely bound around the long-term estimate of the premium at 8.45 , its largest change being only 1.4 basis points. The scale of the variation for the stationary component in the high volatility regime is by far higher than in the non-crisis period, with an estimated annual volatility of 7.238 basis points. 
The distinguishing feature of our model is that it allows us to decompose the term premium into two correlated driving components. The filtered $\mathrm{RW}$ and the stationary components with the associated filtered state probabilities are displayed in Figure 4 and Figure 5. In the first part of the sample period, temporary volatile movements in the RW and stationary components are induced by important albeit 'local' shocks such as the GM and Ford downgrade events of May 2005. In the subsequent period, the credit market enjoyed a rapid growth in terms of both trading volume and product innovation. During this time period, both components stay anchored in the low volatility regime, as reflected by the flat CDX credit curve. The frequent regime changes of the RW component start taking place in the aftermath of Countrywide's bankruptcy. In fact, on August 15, 2007, Countrywide Financial, the largest mortgage lender in the United States, announced that foreclosures and mortgage delinquencies had risen to their highest level since early 2002. Since then, because of that episode and of the events around the onset of the subprime mortgage crisis, the CDX index term premium exhibits a downward trend. 


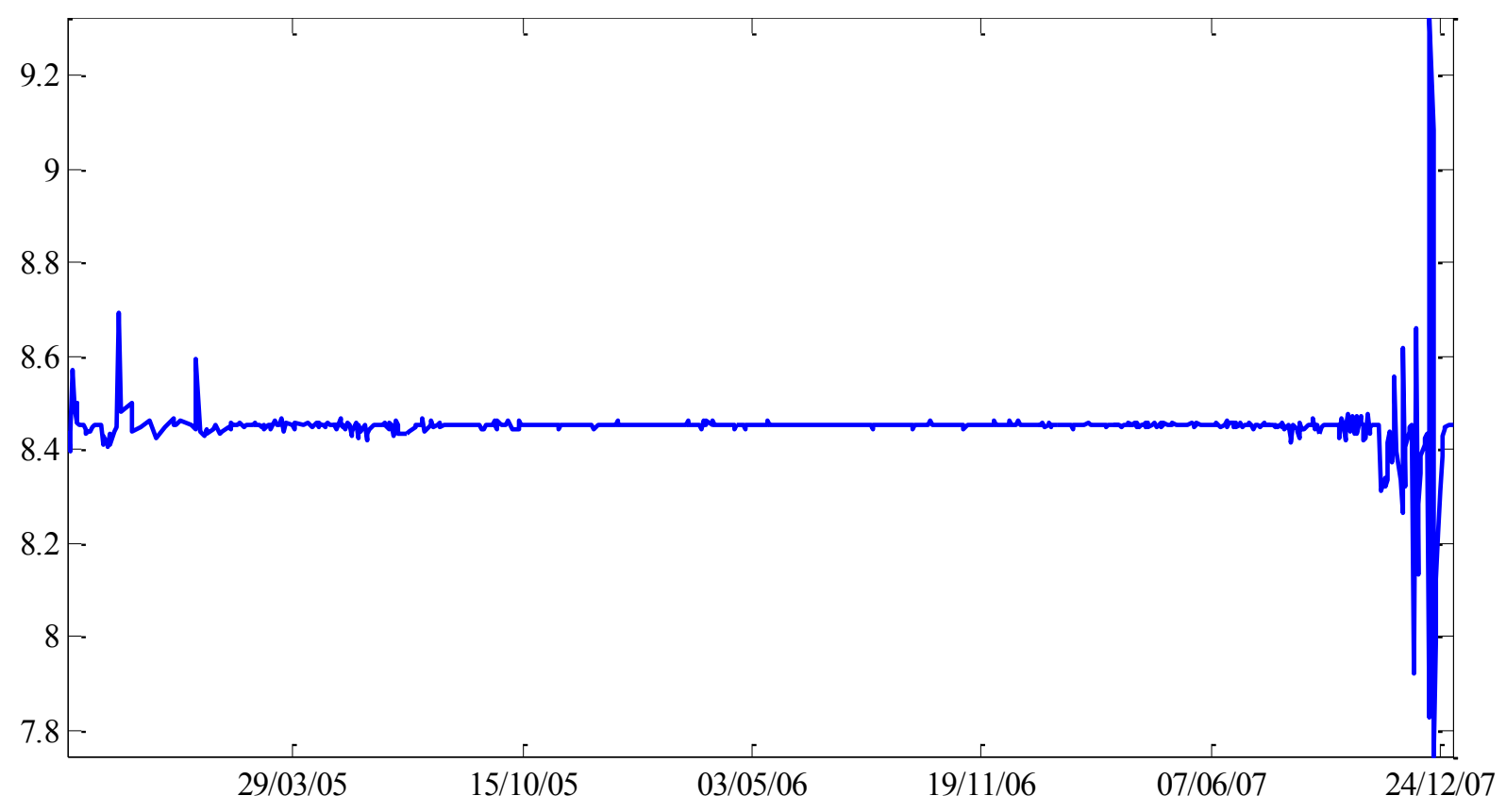

Figure 3: Snapshot of the stationary component in the low volatility regime 


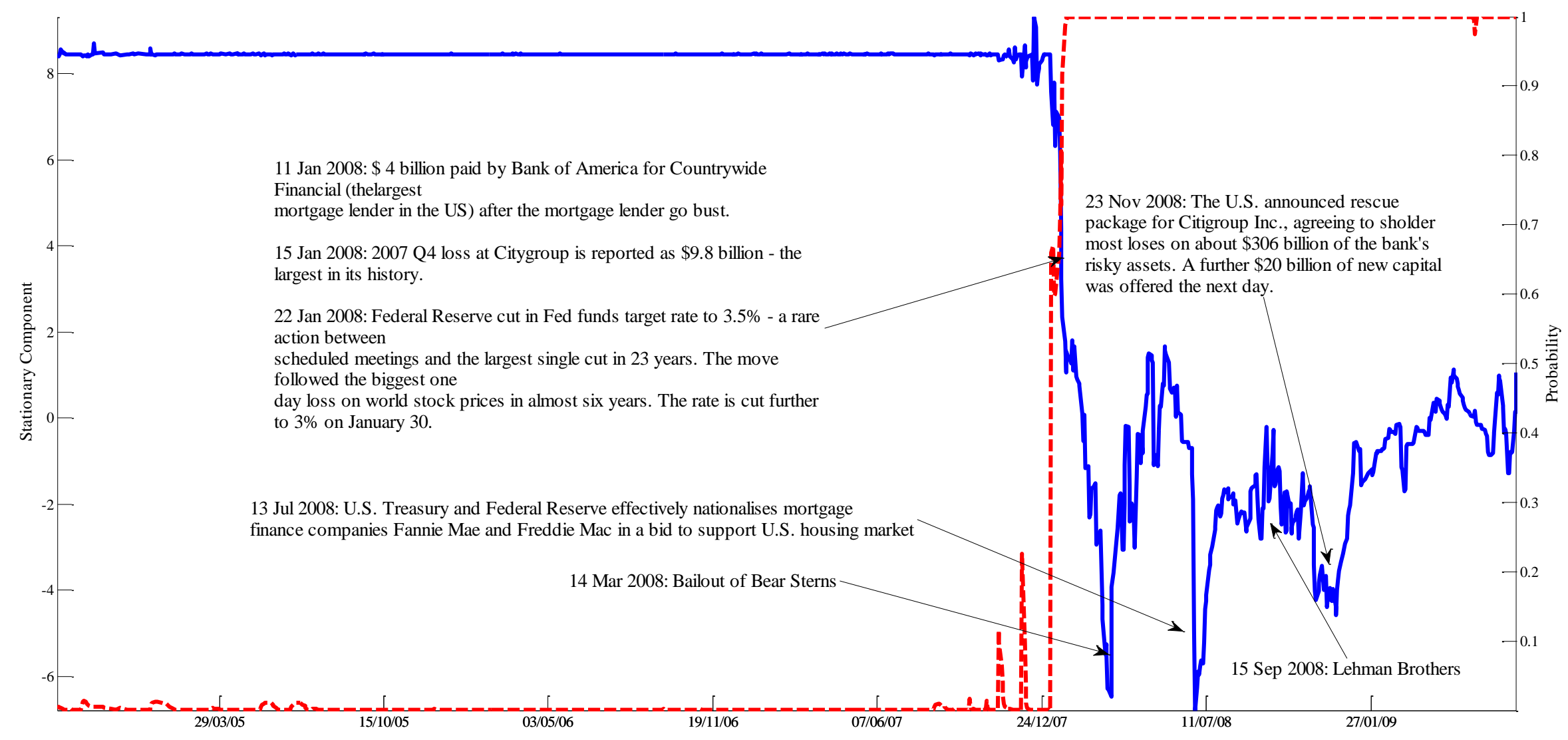

Figure 4: Stationary component and filtered state probability of its high volatility regime 


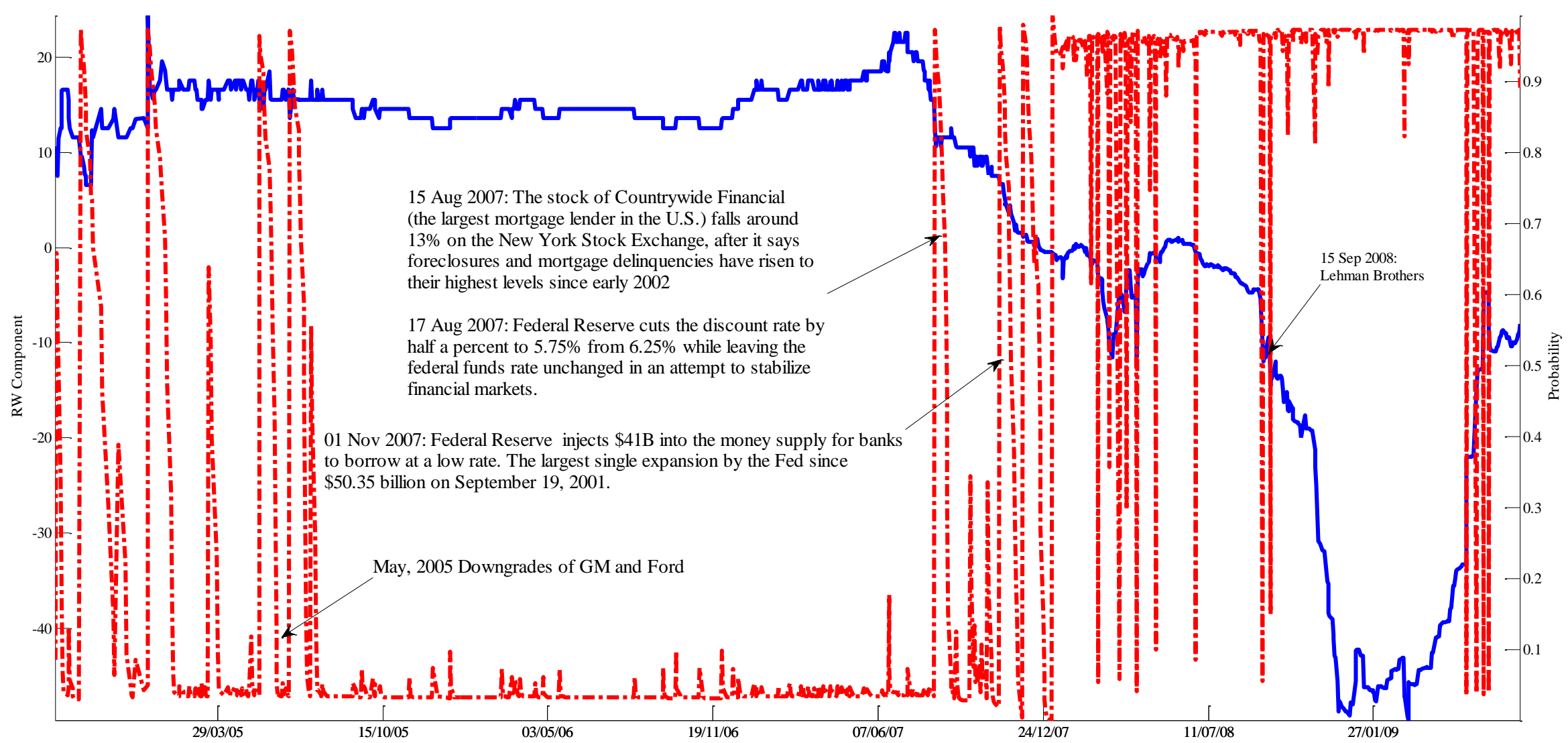

Figure 5: Random walk component and filtered state probability of its high volatility regime 
As shown in Figure 4, the stationary component enters the high volatility period from the beginning of 2008 .

On January 22, 2008, the Federal Reserve cut the Fed funds target rate to $3.5 \%$ - an unprecedented decision, taken between scheduled meetings, and the largest single cut in 23 years. The move followed the biggest one-day loss on world stock exchanges in almost six years. The rate is reduced further to $3 \%$ on January 30, 2008. On March 14, 2008, Bear Sterns' demise brought about a dramatic increase in stock market volatility and liquidity shortages in funding markets. As illustrated in Figure 4, the resulting decline of the stationary component on that day captures an investor confidence-induced downward spiral. The subsequent abrupt jumps occur on July 13, 2008 and November 23, 2008 when the US authorities announced the nationalization of Fannie Mae and Freddie Mac and a rescue package of Citigroup.

Although the filtered state probability of the high volatility regime for stationary component signals accurately greater market volatility since early 2008 , it is quite evident from inspection of this data that the filtered state probability of the high volatility regime for the RW component is close to zero at the occurrence of extreme credit events, such as the Bear Stearn's and Lehman Brothers' default announcements. At first sight, this counterintuitive result may be difficult to understand. It conveys the message that credit market uncertainties, as measured by the conditional variance of the term premium, decline significantly with the abrupt unveiling of tail risk events. Investors have no doubt, they are almost certain, that the markets have entered a new regime characterized by high asset price volatility. 
Conditional variance of the term premium and the filtered state probability of the high volatility regime for Stationary component

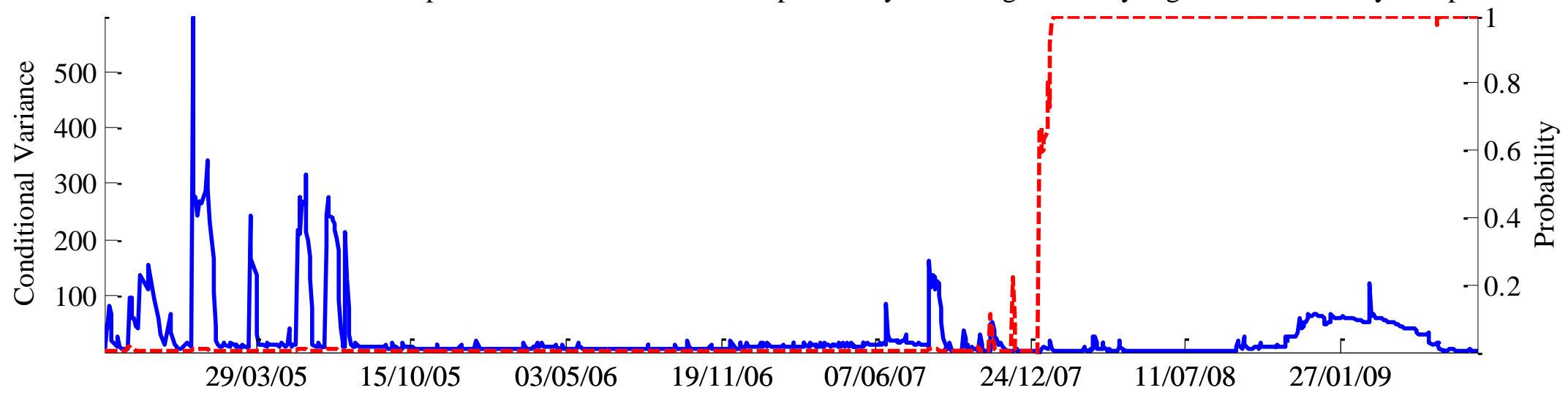

Conditional variance and the term premium and the filtered state probability of the high volatility regime for Random Walk component

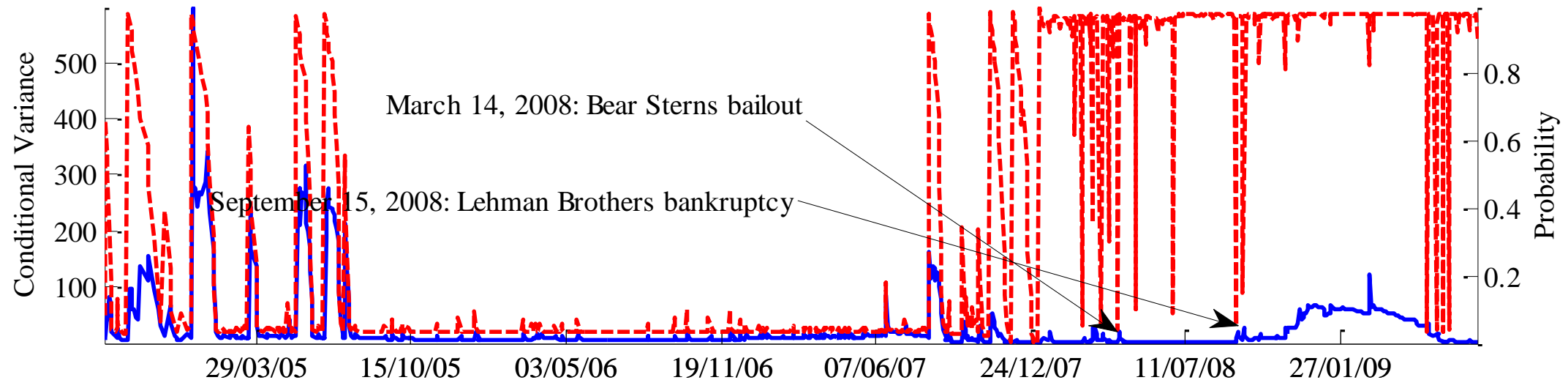

Figure 6: Conditional variance of the term premium (blue line) and filtered state probability of high volatility regime for each component (red line) 
Figure 6 plots the conditional variance derived from Model 8. Using the definition of Kalman filter provided in the previous section, the conditional forecast error variance is given by

$$
f_{t \mid t-1}^{S_{1, t-1} S_{1, t} S_{2, t-1} S_{2, t}}=H P_{t \mid t-1}^{S_{1, t} S_{1, t} S_{2, t-1} S_{2, t}} H^{\prime}
$$

This expression can be regarded as the implied conditional variance of the CDX term premium. Since this conditional variance depends on the two Markov chain processes, combining the filtered probabilities states $\sum_{S_{1, t-1}=0}^{1} \sum_{S_{1, t}=0}^{1} \sum_{S_{2, t-1}=0}^{1} \sum_{S_{2, t}=0}^{1} \operatorname{Pr}\left(S_{1, t-1}=i, S_{1, t}=j, S_{2, t-1}=i, S_{2, t}=j \mid I_{t-1}\right)$ with Equation (15), we calculate the conditional variance as the product of these two terms, based on the available information at time $t-1$. In Figure 6 we observe that the conditional variance, in the immediate aftermath of Bear Stern's bailout (March 14, 2008), remains at low levels for a few days. What is particularly striking is that the filtered probability of the high volatility regime for the RW component falls back to a near-zero value at the outbreak. However, within a very short period of time it does returns back to the high volatility regime. Such behavior is rather challenging to explain. We conjecture that the initial view taken by the market on the bailout was benign and was then reversed. In periods of unprecedented volatility/financial uncertainty the time required for the in-depth evaluation of policy measures may be longer than in 'normal times'. The markets may react positively to good news but once they make their assessment on the full implications such views may change, if the policy responses are deemed inadequate given the distressed conditions of financial markets.

In the sub-sample period surrounding Lehman Brothers' default, the conditional variance of the CDX term premium is higher than in the Bear Stern's bailout period, as a consequence, the state probability of the high volatility regime for RW component initially falls back to near-zero value, but rebounds very rapidly in the subsequent days as investors begin to worry 
about the stability of other systemically important financial institutions. Our results show that the coherence between the high conditional variance of the CDX term premium and the state probability of the high volatility regime for RW component disappears during the financial crisis period. This suggests that the RW and the stationary components behaved differently depending upon whether the financial system is experiencing a systemic crisis.

\subsection{VAR Analysis}

We now test for the impact of observed economic and financial variables on the unobserved stationary and RW components, in the context of the following VAR (4) model ${ }^{5}$

$$
Y_{t}=c+\Pi_{1} Y_{t-1}+\Pi_{2} Y_{t-2}+\Pi_{3} Y_{t-3}+\Pi_{4} Y_{t-4}+\varepsilon_{t}
$$

where $Y_{t}$ includes the stationary $(S T A T)$ and changes in the RW components $(D I F R W)$, the observed level of effective US Federal Fund Rate $(F F R)$, the slope of the yield curve (SLOPE101, calculated as the difference between 10-year and 1-year US treasury bond yields), the Standard \& Poor's 500 index return (SP500RTN), and the implied volatility of the Standard \& Poor's 500 index $(L O G V I X)^{6} . c$ is a $(6 \times 1)$ vector of constants, $\Pi_{i}$ are $(6 \times 6)$ coefficient matrices and $\varepsilon_{t}$ is an $(6 \times 1)$ unobservable zero mean white noise vector process with invariant covariance matrix $\Sigma$. Given a structural break happened in January 2008, we split the sample into two periods depending on the two volatility regimes of the stationary component. The first sub-sample varies from September 13th, 2004 to January 3rd, 2008 and the second sub-sample starts from January 4th, 2008 to July 23rd, $2009^{7}$.

\footnotetext{
${ }^{5}$ The order of the VAR is established using the SBC criterion.

${ }^{6} Y_{t}=\left[F_{t}, S L O P E 101_{t}, \text { SP500RTN }_{t}, \text { LOGVIX }_{t}, \text { DIFRW }_{t}, \text { STAT }_{t}\right]^{\prime}$

${ }^{7}$ The dates for the sample division for the VAR have been chosen based on the date when the probability of the stationary component jumps to unity indicating the transition to the high volatility regime (Figure 4)
} 
Accumulated Response of DIFRW to FFR

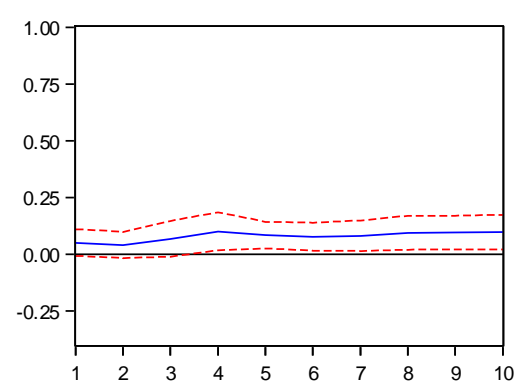

Accumulated Response of DIFRW to DIFRW

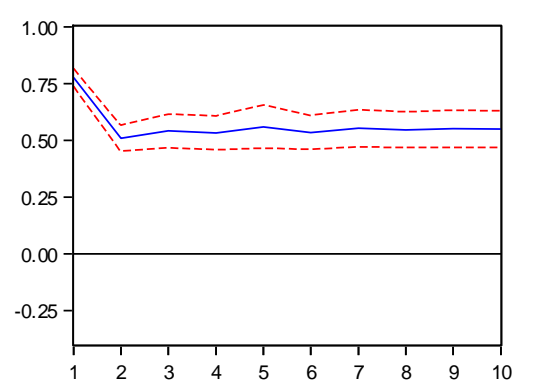

Accumulated Response of STAT to SP500RTN

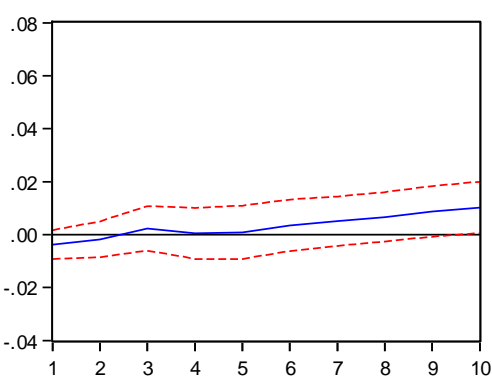

Accumulated Response to Generalized One S.D. Innovations \pm 2 S.E.

Accumulated Response of DIFRW to SLOPE101 Accumulated Response of DIFRW to SP500RTN

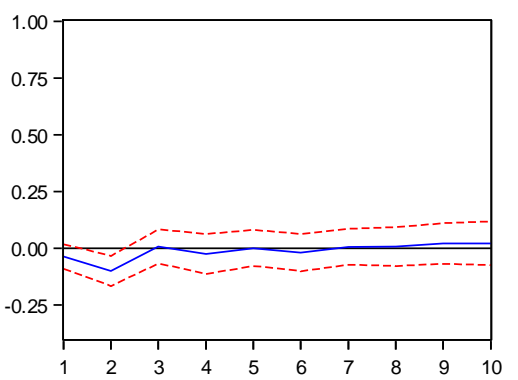

Accumulated Response of DIFRW to STAT

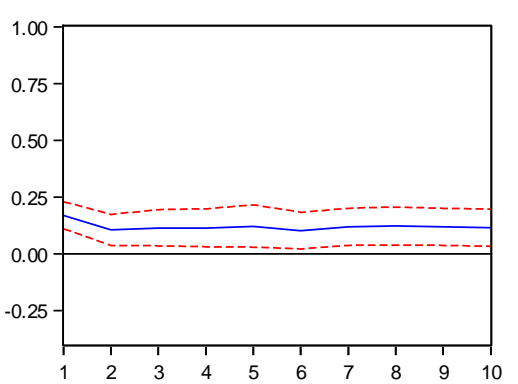

Accumulated Response of STAT to LOGVIX

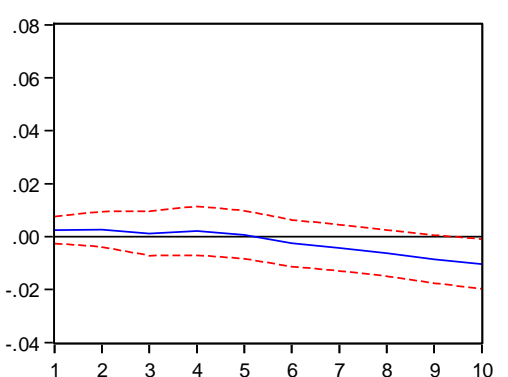

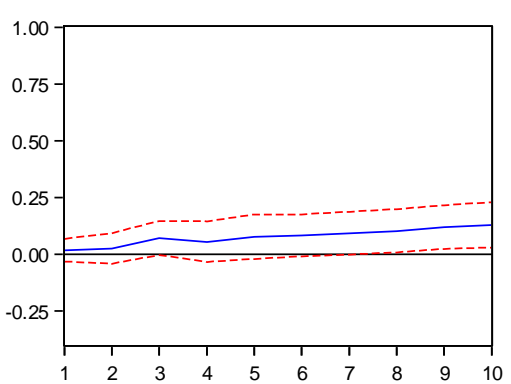

Accumulated Response of STAT to FFR

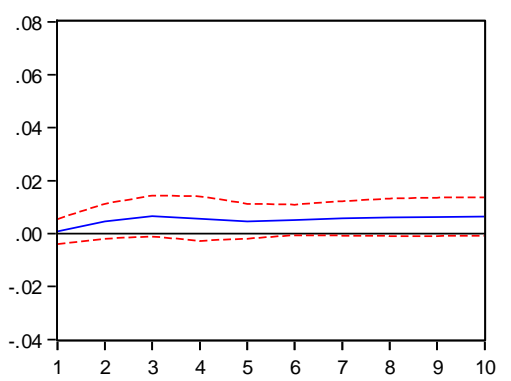

Accumulated Response of STAT to DIFRW

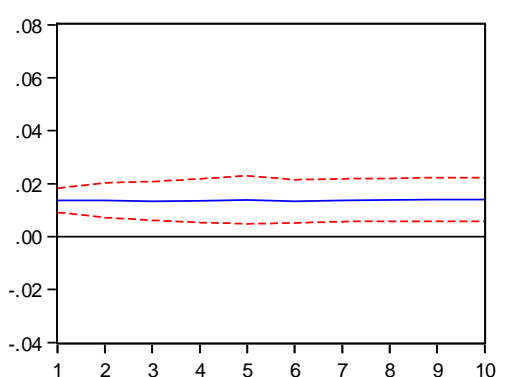

Accumulated Response of DIFRW to LOGVIX

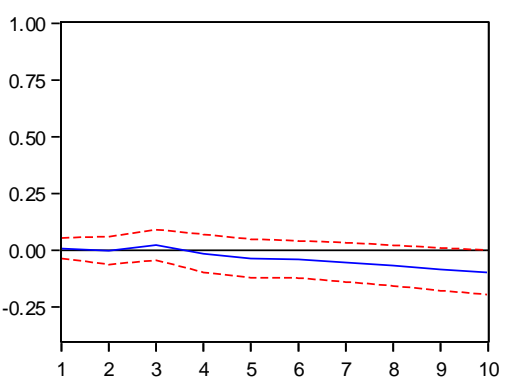

Accumulated Response of STAT to SLOPE101

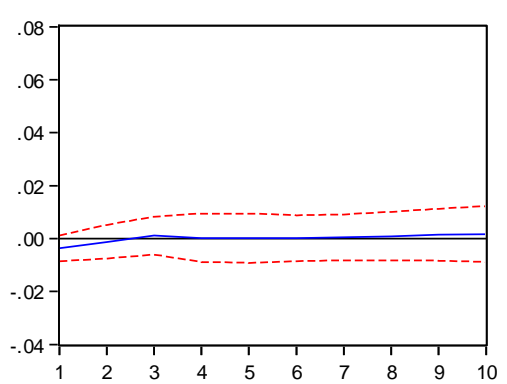

Accumulated Response of STAT to STAT

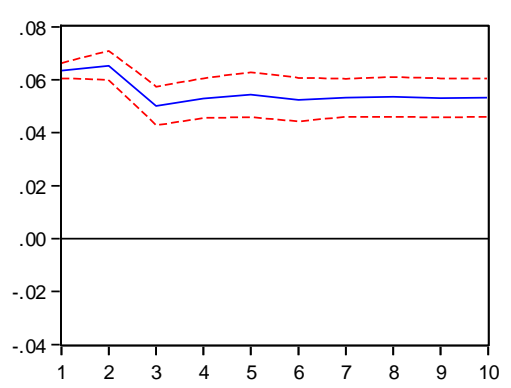

Figure 7: Accumulative generalized impulse response functions of the VAR model in the pre-financial crisis period (September 13, 2004 to January 03, 2008) 
Accumulated Response of DIFRW to FFR

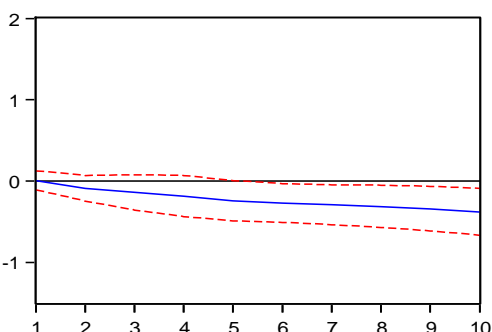

Accumulated Response of DIFRW It DIFRW

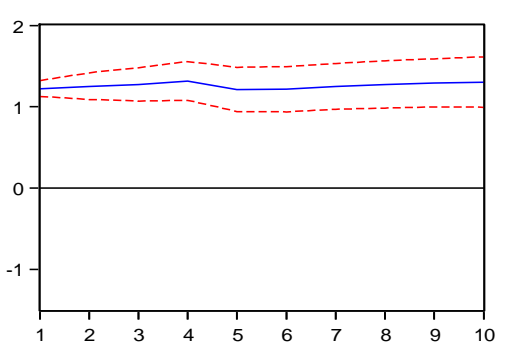

Accumulated Response of STAT to SP500RTN

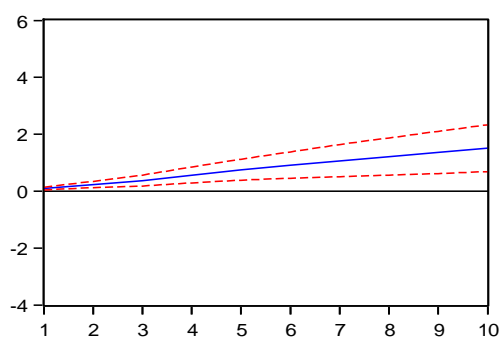

Accumulated Response to Generalized One S.D. Innovations \pm 2 S.E. Accumulated Response of DIFRW to SLOPE101

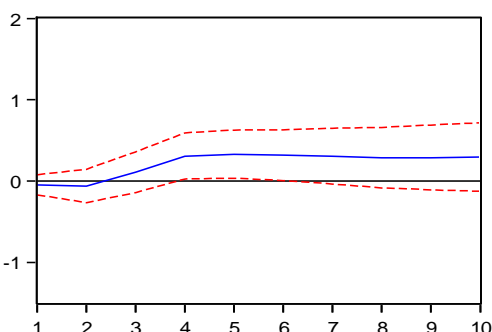

Accumulated Response of DIFRW to STAT

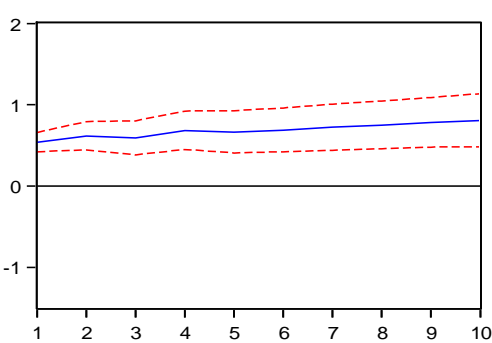

Accumulated Response of STAT to LOGVIX

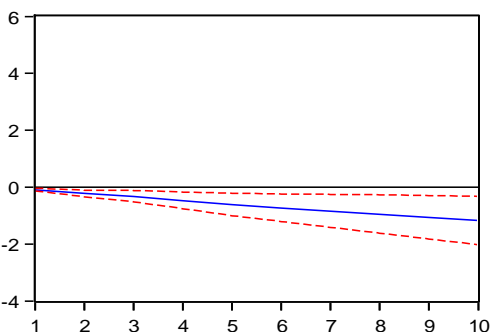

Accumulated Response of DIFRW to SP500RTN

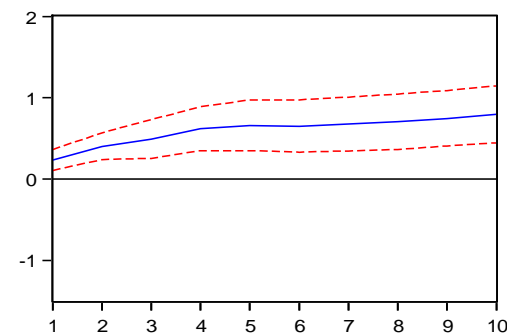

Accumulated Response of DIFRW to LOGVIX

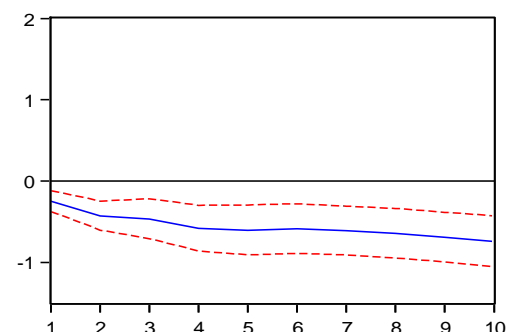

Accumulated Response of STAT to FFR

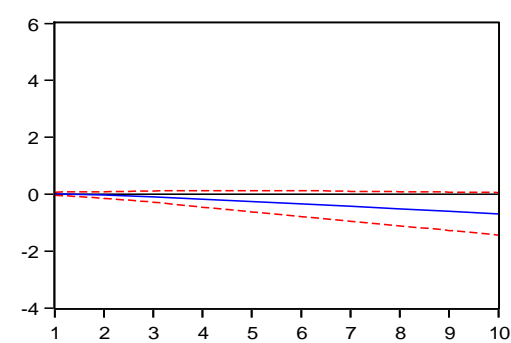

Accumulated Response of STAT to DIFRW

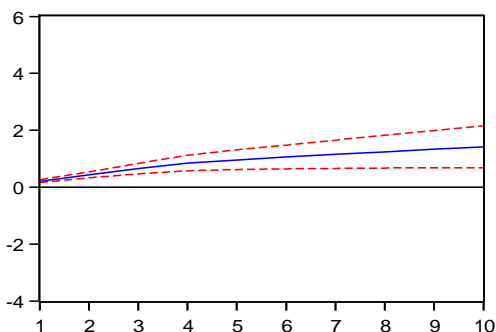

Accumulated Response of STAT to SLOPE10

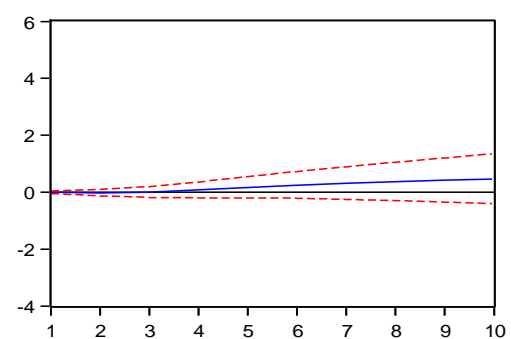

Accumulated Response of STAT to STAT

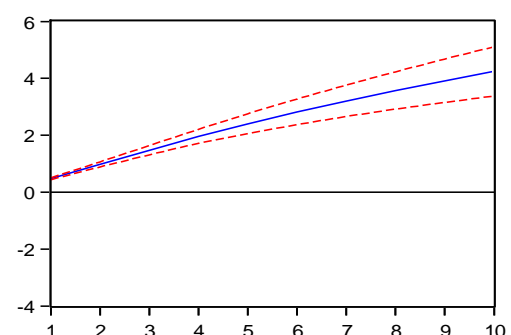

Figure 8: Accumulative generalized impulse response functions of the VAR model in the post-financial crisis period (January 04, 2008 to July 23, 2009) 
To evaluate the relationships between the two components and monetary policy and stock market variables, we compute the accumulated generalized impulse response functions, which trace out the responsiveness of the dependent variables to one unit generalized shock to each of the variables in the VAR system. These impulse response functions provide useful insights into the dynamic properties of the system.

As forecasting variables of the variation in the term premium of the CDX index, these monetary policy and stock market variables appear to impact differently on the two components, before and after the onset of the crisis. Figure 7 shows the accumulated generalized impulse response functions of the VAR model in the pre-crisis period. The responses of DIFRW and STAT to FFR are significantly positive, which is consistent with the findings of Longstaff and Schwartz (1995) who document that corporate yield spreads vary inversely with the benchmark short-term treasury yield. Since an increase in the monetary policy rate would translate into an increase in the level of interest rate in normal periods, a higher interest rate level will decrease the present value of future cash flows and hence the value of default protection. This would lead to a tightening of the credit spread. If the tightening of the spread were more severe for the shorter CDS maturities, the term premium in the credit curve would increase as represented by a rise in the slope of the credit curve. This result, as illustrated in Figure 7, is also consistent with Longstaff and Schwartz (1995) who suggest that the relationship between the CDX index spread and the risk-free interest rate depends on the time horizon. Compared to the negative responses of DIFRW and STAT in Figure 8, an increase in the monetary policy rate in the crisis-period would sharply reduce liquidity, increasing the probability of imminent default. The obvious effect would be widening the 5-year CDX spread and flattening the term premium of the CDX index. The Fed's response in reducing the Federal funds rate rapidly during 2008 prevented the flattening of the CDS term structure as it can be seen from the impulse response function in 
figure 8 where it depicts a negative impulse response of the random walk component of the term premium to a positive shock of the Federal Funds Rate. An increase in the Federal Fund Rate would have resulted in an increase of the 5-year premium, the Fed by decreasing rates allowed for lowering this premium, moderating the slope of the inversion of the curve. This timely response of the Fed played an important role in avoiding dramatic increases in the short (5-year) premia and therefore helped stabilizing the short-term segment of the CDS market.

The responses of the two components to SLOPE101 are negative but insignificant during the pre-crisis period. Bedendo, Cathcart and El-Jahel (2007) report a negative relationship between the slope of the treasury yield curve and credit spreads. The reason is that when a positively sloped yield curve is the outcome of an expansionary monetary policy, which will increase future firm value and reduce default risk, then the term premium decreases due to falls in the 10-year spread. At the same time a steeper yield curve in normal time periods may indicate an increase in the future short rate through the expectations channel. If the inflation risk premium on longer term interest is very low (or even negative, see (Kim and Wright (2005)), long term interest rates would change little in response to a continuous rise in short term rates (Smith and Taylor (2009)). This effect, known as the "Conundrum", may make the shorter maturity default protection contract more expensive than those with longer maturities and hence, increase the 5-year credit risk premium, reducing the term premium of $\mathrm{CDX}$ index. In contrast during the crisis time period, any increase in the slope of yield curve that caused by reduction in short rate would be regarded as a signal of liquidity provided from central banks in order to ameliorate the impact of the recession on the balance sheets of the firms. Default protection premia (5-year) will fall and this would subsequently lead to an increase in the term premium. The positive responses of 
both DIFRW and STAT to an increase in the slope of yield curve in crisis period (Figure 8) lend support to this hypothesis.

In the pre-crisis period the initial responses to equity market returns and the implied volatility index, have the opposite signs on DIFRW and STAT at the outset. Yet, at longer lags, both components exhibit a positive (negative) relationship with the equity returns (equity volatility). During the post-crisis period this initial divergence dissipates and both factors strongly respond positively to equity returns and negatively to the VIX. Such finding is consistent with the evidence in Byström (2006) who reports that on-the-run single-name CDS spread is significantly negatively related to the equity returns for the period 2004-2006. Scheicher (2009) also demonstrates that there is a significant contemporaneous link between the CDS market and the stock market. The inverse relationship between the two components and equity return volatility is broadly consistent with previous econometric evidence, as illustrated by Campbell and Taksler (2003), Alexander and Kaeck (2008) and Zhang (2008). In the theoretical framework of Merton (1974), higher equity volatility means higher probability of hitting the default barrier which induces a higher compensation for holding the bond in the form of larger credit spread. Although the positive (negative) responses to equity return (equity return volatility) hold both in non-crisis and crisis periods, the magnitude of responses in crisis period is far more pronounced.

To quantify the impact of all the observed variables on the unobserved factor we compute the generalized variance decomposition ${ }^{8}$ over the two periods and the results are presented on Tables 8 and 9. The key finding is the presence of strong effects attributable to stock market variables on both components before and after the crisis. Initially, in the precrisis period the impact of all the variables on both components is modest (Table 8). Stock market returns and their volatility appear to be the variables exerting some influence on

\footnotetext{
${ }^{8}$ See Koop, Pesaran and Potter (1996) and Pesaran and Shin (1998)
} 
DIFRW and STAT. Collectively they account for $7.5 \%$ of DIFRW variability's and $3.51 \%$ of STAT's variance.

In the post-crisis period of our sample (Table 9), approximately $13.5 \%$ in the variation in DIFRW can be attributed to a combination of stock market variables, the monetary policy and the slope of the yield curve. More specifically the proportion accounted by the stock market variables is $7.68 \%$. For the stationary component the same information set explains $16.44 \%$ of the variance a nearly fivefold increase compared to the previous period. The impact of monetary policy alone is $4.2 \%$ compared to its previous value of $0.5 \%$.

Importantly, our results indicate that in the crisis period information pertinent to the immediate valuation of firm's assets such as the stock market index and monetary policy exerted relatively strong influence on the variance of the term premium, compared to factors such as VIX and the slope of the yield curve.

Within the confines of the model, the crisis period is indicative of a significant change to the fundamentals that determine the term premium, as captured by the stationary component. The evidence from the RW component is indicative of increased volatility that can be only partly explained by the set of the observed macro and financial variables included in our analysis.

In summary, these results do provide evidence that the inversion of the term premium since the onset of the crisis is primarily attributable to the evolution of the stock market and monetary policy.

Table 8: Generalized variance decomposition of DIFRW and STAT in the pre-financial crisis period(September 13, 2004 to January 03, 2008)

\begin{tabular}{c|c|c|c|c|c|c|c}
\hline \hline \multicolumn{7}{c}{ Variance Decomposition of DIFRW: } \\
\hline Period & S.E. & FFR & SLOPE101 & SP500RTN & LOGVIX & DIFRW & STAT \\
\hline$\vdots$ & & & & & & & \\
\hline 10 & 0.838 & 0.695 & 2.746 & 0.446 & 3.284 & 92.716 & 0.113 \\
\hline 15 & 0.839 & 0.698 & 2.758 & 0.505 & 3.307 & 92.615 & 0.116 \\
\hline
\end{tabular}


Variance Decomposition of STAT:

\begin{tabular}{c|c|c|c|c|c|c|c}
\hline$\vdots$ & & & & & & & \\
\hline 10 & 0.065 & 0.506 & 0.579 & 1.209 & 0.875 & 4.320 & 92.512 \\
\hline 15 & 0.065 & 0.509 & 0.579 & 1.445 & 0.973 & 4.307 & 92.186 \\
\hline \hline
\end{tabular}


Table 9: Generalized variance decomposition of DIFRW and STAT in the post-financial crisis period (January 04, 2008 to July 23, 2009)

\begin{tabular}{c|c|c|c|c|c|c|c}
\hline \hline \multicolumn{7}{c}{ Variance Decomposition of DIFRW: } \\
\hline Period & S.E. & FFR & SLOPE101 & SP500RTN & LOGVIX & DIFRW & STAT \\
\hline$\vdots$ & & & & & & & \\
\hline 10 & 1.249 & 1.284 & 4.203 & 6.314 & 1.090 & 86.421 & 0.688 \\
\hline 15 & 1.254 & 1.577 & 4.174 & 6.556 & 1.127 & 85.794 & 0.773 \\
\hline \multicolumn{7}{|c|}{ Variance Decomposition of STAT: } \\
\hline$\vdots$ & 1.381 & 2.837 & 1.213 & 9.592 & 0.210 & 8.664 & 77.485 \\
\hline 10 & 1.538 & 4.258 & 1.171 & 10.837 & 0.173 & 7.502 & 76.059 \\
\hline 15 &
\end{tabular}

\section{Conclusion}

In this article, we estimate a Markov switching unobserved component model to explain the evolution of the term premium of the most liquid CDS maturities for the North American CDX index. We consider an appropriately specified Markov Switching Unobserved Components model as a reliable measure of volatility dynamics of the CDX index spread curve and investigate the presence and significance of both monetary policy adjustments and stock market returns for the US economy over the sample period September 2004 - July2009.

To the best of our knowledge, this is the first direct empirically based evidence that is brought on the evolution of the term premium of the CDS index market and its observed macroeconomic and financial determinants.

To capture the magnitude of uncertainty in the credit risk transfer market, we decompose the level of the CDX index term premium into two components. The first, the RW component is assumed to capture the changes in volatility driving the term premium whereas the second, a stationary AR(1) process, represents the fundamentals. Furthermore, we formulate a model with time-varying regime switching probabilities and regime dependent components. 
Our results suggest that the inversion of the curve around September 2008 is largely driven by abrupt moves in the stationary component, representing the evolution of the fundamentals underpinning the probability of default in the economy. The component enters the high volatility regime after a prolonged period of remarkable stability. Notably, by the end of 2007, the stationary component exhibits slight turbulence in the low volatility regime, but of a very different order of magnitude from the subsequent evolution of the component in 2008. The decline of the term premium accelerates sharply throughout the end of 2007 when it partially reverses its trend remains. However, it remains in the high volatility regime in the final part of the sample period. Interestingly, although the RW component appears to evolve in a very stable and predictable manner from 2004 to 2008, fluctuates somewhat intensively between the low and high volatility regime over short periods of time during 2005 and by the end of 2007. From the beginning of the sub-prime crisis in August 2007 the component exhibits downward movement but does not enter decisively the high volatility regime. Over the last part of the sample, the component enters more frequently the low-volatility regime but in a rather unpredictable manner, indicating that the uncertainty which surrounds asset values remains unabated.

Remarkably, the inclusion of observed economic and financial variables to predict the evolution of the unobserved components does a relatively good job only during the 'crisis' period. These variables are found to make a statistically significant contribution that is consistent with economic theory. Indeed, we find robust evidence that the unprecedented monetary policy response, of sharp rate reductions by the Fed during the crisis period, was effective in reducing market uncertainty and helped to steepen the curve of the index thereby mitigating immediate concerns regarding systemic risk. The impact of stock market volatility in flattening the curve and exerting comparatively higher upward pressure on the 5-year CDX is substantially more robust in the crisis period, as both components are significantly affected 
by the VIX measure. It also appears that equity returns are important drivers of the term premium during both periods. This impact results in a steepening of the curve as the current value of the underlying 'collateral' increases. Our results also suggest that in the pre-crisis period the RW component associated with increased volatility displays a low reaction to the stock market. Additionally, as expected the impact on the stationary component albeit positive is not significant. Yet, from January 01, 2008 both components respond immediately and significantly to stock market fluctuations. We demonstrate that the unprecedented stock market collapse is a very important contributory factor to the inversion of the CDX index term premium.

Overall, this evidence implies that credit risk modeling that ignores this regime dependent feature would bias the pricing of credit contracts. Developments in both the first and second moments of the equity market have a lasting influence on both components, with more pronounced effects during volatile market conditions.

The evolution of the CDX index in all maturities is an important signal of the 'health' of the economy over the short and long run. Sudden inversions indicate sharp deterioration of the current economic conditions and increased probability of default. Such movements are triggered by both the evolving stance of monetary policy and developments in the equity markets that make a significant albeit modest contribution to their predictability.

This article is only a first step toward the development of a fully-fledged consistent framework to gain greater insight in the dynamics of the CDX curve indices across different parts of the credit cycle and in the relationship between the shape of the term structure and macro/financial variables fluctuations. Further research is warranted. Interesting possibilities for further research include the consideration of an extended number of maturities and of other index tranches, such the high-yield segment of the market. These extensions along with a complementing examination of liquidity risks and the risk of spillovers will enhance our 
understanding of the dynamics of such important markets, primarily from a systemic viewpoint. 


\section{APPENDIX A}

\section{Estimation Procedure}

To estimate the state space Markov switching model, described in detail in the previous subsections, we use Kim's filter (Kim (1994)), which is a numerical algorithm that combine the Kalman filter in estimating state space models and the Hamilton filter in estimating Markov switching models. In the conventional derivation of the Kalman filter for an invariant parameter state space model, the goal is to make predictions of the unobserved state variables based on the current information set, denoted $X_{t t-1}=\mathrm{E}\left(X_{t} \mid I_{t-1}\right)$, where $I_{t-1}$ represents all observed variables available at time $t-1$. The mean squared error of the prediction, denoted as $P_{t \mid t-1}$, is $P_{t \mid t-1}=\mathrm{E}\left(\left(X_{t}-X_{t \mid t-1}\right)\left(X_{t}-X_{t \mid t-1}\right)^{\prime} \mid I_{t-1}\right)$. The Kalman filter algorithm then implements a sequence of Bayesian updating on the unobserved variable $X_{t}$ and the mean square error $P_{t}$ when observing a new data entry. The updated unobserved variable $X_{t \mid k}$, given the observation of the information set at time $t$, is formed as a weighted average of $X_{t \mid t-1}$ and new information contained in the prediction error, where the weight assigned to this new information is called Kalman gain. This prediction and updating process evolves over time and is conditional on the correctly estimated parameters of the model. As a result, Kalman filter will need to be initialized in the first place with some carefully chosen initial values. Then, the prediction errors and their variances, as the by-products of the prediction process, will be used to construct the log-likelihood function

$$
L(\theta)=-\frac{1}{2} \sum \ln \left[(2 \pi)^{n}\left|\omega_{t \mid t-1}\right|\right]-\frac{1}{2} \sum \psi_{t \mid t-1}^{\prime} \omega_{t \mid t-1}^{-1} \psi_{t \mid t-1}
$$

\section{EQUATION 17}

where $\psi_{t \mid t-1}$ is the prediction error and $\omega_{t \mid t-1}$ is its conditional variance.

For our model, however, the Markov variables $S_{1, t}$ and $S_{2, t}$, as the additional unobserved variables in the state space system, would undoubtedly complicate the estimation procedures. The prediction and updating processes in the Markov switching state space system now will additionally depend on both the previous and current values of the Markov variables. Since we have two independent Markov chain processes in our model, for given 
realizations of the two Markov variables at times $t$ and $t-1\left(S_{1, t-1}=i, S_{1, t}=j, S_{2, t-1}=i\right.$ and $S_{2, t}=j$, where $\left.i=\{0,1\}, j=\{0,1\}\right)$, the Kalman filter equations can then be represented as follows

$$
\begin{aligned}
& X_{t \mid t-1}^{S_{1,-1} S_{1, S} S_{2, t-1} S_{2, t}}=C+F X_{t-1 \mid t-1}^{S_{1, t} S_{2, t-1}} \\
& P_{t \mid t-1}^{S_{1, t-1} S_{1, t} S_{2, t-1} S_{2, t}}=F X_{t-1 \mid t-1}^{S_{1,-1} S_{2, t-1}} F^{\prime}+\Sigma^{S_{1, t} S_{2, t}} \\
& \eta_{t \mid t-1}^{S_{1, t-1} S_{1, t} S_{2, t-1} S_{2, t}}=Y_{t}-H X_{t \mid t-1}^{S_{1, t} S_{1, t} S_{2, t-1} S_{2, t}} \\
& f_{t \mid t-1}^{S_{1, t-1} S_{1, t} S_{2, t-1} S_{2, t}}=H P_{t \mid t-1}^{S_{1, t-1} S_{1, t} S_{2, t-1} S_{2, t}} H^{\prime} \\
& X_{t \mid t}^{S_{1, t-1} S_{1, t} S_{2, t-1} S_{2, t}}=X_{t \mid t-1}^{S_{1, t-1} S_{1, S} S_{2, t-1} S_{2, t}}+\frac{P_{t|t|-1}^{S_{1, t} S_{1, t} S_{2, t-1} S_{2, t}} H^{\prime}}{f_{t \mid t-1}^{S_{1,-1} S_{1, t} S_{2, t-1} S_{2, t}}} \eta_{t \mid t-1}^{S_{1, t-1} S_{2, t-1}} \\
& P_{t \mid t}^{S_{1, t-1} S_{1, t} S_{2, t-1} S_{2, t}}=P_{t \mid t-1}^{S_{1, t} S_{1, t} S_{2, t-1} S_{2, t}}-\frac{P_{t \mid t-1}^{S_{1, t-1} S_{l, t} S_{2, t-1} S_{2, t}} H^{\prime} H P_{t \mid t-1}^{S_{1, t-1} S_{1, S} S_{2, t-1} S_{2, t}}}{f_{t \mid t-1}^{S_{1, t} S_{1, t} S_{2, t-1} S_{2, t}}}
\end{aligned}
$$

\section{EQUATION 18}

where $X_{t-1 \mid t-1}^{S_{1, t} S_{2,-1}}$ is the value of $X_{t-1}$ based on the information up to time $t-1$, given that $S_{1, t-1}=i$ and $S_{2, t-1}=i ; X_{t \mid t-1}^{S_{1,-1} S_{1, t} S_{2, t-1} S_{2 t}}$ is the updated value of $X_{t}$ based on the information up to time $t-1$, given that $S_{1, t-1}=i, S_{1, t}=j, S_{2, t-1}=i$ and $S_{2, t}=j ; P_{t \mid t-1}^{S_{1, t} S_{1, t} S_{2, t-1} S_{2, t}}$ is the mean squared error of the unobserved $X_{t \mid t-1}^{S_{1, t} S_{1, t} S_{2, t-1} S_{2, t}}$ given $S_{1, t-1}=i, S_{1, t}=j, S_{2, t-1}=i$ and $S_{2, t}=j ; \eta_{t \mid t-1}^{S_{1, t-1} S_{1, t} S_{2, t-1} S_{2, t}}$ is the prediction error of $Y_{t}$ in the measurement equation, given the updated forecast of $X_{t}$ as $X_{t \mid t-1}^{S_{1, t} S_{1, S} S_{2, t-1} S_{2, t}}$ conditional on $S_{1, t-1}=i, S_{1, t}=j, S_{2, t-1}=i$ and $S_{2, t}=j$ based on the information up to time $t-1 ; f_{t \mid t-1}^{S_{1, t-1} S_{1, t} S_{2, t-1} S_{2, t}}$ is the conditional variance of the forecast error $\eta_{t \mid t-1}^{S_{1, t-1} S_{1, t} S_{2, t-1} S_{2, t}}$; $X_{t \mid t}^{S_{1, t-1} S_{1, t} S_{2, t-1} S_{2, t}}$ and $P_{t \mid t}^{S_{1, t-1} S_{1, t} S_{2, t-1} S_{2, t}}$ are the updated $X_{t}$ and $P_{t}$ based on the information up to time $t$ , given that $S_{1, t-1}=i, S_{1, t}=j, S_{2, t-1}=i$ and $S_{2, t}=j$.

Since each iteration of the Kalman filter produces a 4-fold increase in the number of cases to consider ${ }^{9}$, we reduce the 16 one-period posteriors $X_{t \mid t}^{S_{1, t-1} S_{1, t} S_{2, t-1} S_{2, t}}$ and $P_{t \mid t}^{S_{1, t-1} S_{1, t} S_{2, t-1} S_{2, t}}$ into 4 by taking appropriate approximations at the end of each iteration. This is computed through Kim's approximation procedures

\footnotetext{
${ }^{9}$ We have 4 cases to consider in each iteration of the Kalman filter: (1) both stationary and RW components are in high volatility regime; (2) stationary component is in the high volatility regime while the RW component is in the low volatility regime; (3) stationary component is in the low volatility regime while the RW component is in the high volatility regime; (4) both stationary and RW components are in low volatility regime. Therefore, every new iteration, the first order dependence of the current Markov chain variable on its previous value leads to a 4fold increase in the number of cases to consider.
} 


$$
X_{t \mid t}^{S_{1, t} S_{2, t}}=\frac{\sum_{S_{1, t-1}=0}^{1} \sum_{S_{2, t-1}=0}^{1} \operatorname{Pr}\left(S_{1, t-1}=i, S_{1, t}=j, S_{2, t-1}=i, S_{2, t}=j \mid I_{t}\right) X_{t \mid t}^{S_{1, t} S_{1, t-1} S_{2, t} S_{2, t-1}}}{\operatorname{Pr}\left(S_{1, t}=j, S_{2, t}=j \mid I_{t}\right)}
$$

\section{EQUATION 19}

$$
\begin{aligned}
P_{t \mid t}^{S_{1, t} S_{2, t}}= & \sum_{S_{1, t}=0}^{1} \sum_{S_{2, t}=0}^{1}\left(P_{t \mid t}^{S_{1, t} S_{1, t-1} S_{2, t} S_{2, t-1}}+\left(X_{t \mid t}^{S_{1, t} S_{2, t}}-X_{t \mid t}^{S_{1, t} S_{1, t-1} S_{2, t} S_{2, t-1}}\right)\left(X_{t \mid t}^{S_{1, t} S_{2, t}}-X_{t \mid t}^{S_{1, t} S_{1, t-1} S_{2, t} S_{2, t-1}}\right)^{\prime}\right) \\
& \times \frac{\operatorname{Pr}\left(S_{1, t-1}=i, S_{1, t}=j, S_{2, t-1}=i, S_{2, t}=j \mid I_{t}\right)}{\operatorname{Pr}\left(S_{1, t}=j, S_{2, t}=j \mid I_{t}\right)}
\end{aligned}
$$

\section{EQUATION 20}

where the probability terms in the above two equations are obtained from Hamilton's filter as

$$
\begin{aligned}
& \operatorname{Pr}\left(S_{1, t-1}=i, S_{1, t}=j, S_{2, t-1}=i, S_{2, t}=j \mid I_{t}\right) \\
& =\frac{\operatorname{Pr}\left(Y_{t} \mid S_{1, t-1}=i, S_{1, t}=j, S_{2, t-1}=i, S_{2, t}=j, I_{t-1}\right) \operatorname{Pr}\left(S_{1, t-1}=i, S_{1, t}=j, S_{2, t-1}=i, S_{2, t}=j \mid I_{t-1}\right)}{\operatorname{Pr}\left(Y_{t} \mid I_{t-1}\right)}
\end{aligned}
$$

with

$$
\begin{aligned}
& \operatorname{Pr}\left(Y_{t} \mid S_{1, t-1}=i, S_{1, t}=j, S_{2, t-1}=i, S_{2, t}=j, I_{t-1}\right) \\
& =\frac{1}{\sqrt{(2 \pi)^{N} \mid f_{t \mid t-1}^{S_{1, t} S_{1, t-1}, S_{2, t} S_{2, t-1} \mid}}} \exp \left(-\frac{1}{2} \frac{\left(\eta_{t \mid t-1}^{S_{1, t-1} S_{2, t-1}}\right) \cdot\left(\eta_{t \mid t-1}^{S_{1, t-1} S_{2, t-1}}\right)}{f_{t \mid t-1}^{S_{1, t} S_{1, t-1}, S_{2, t} S_{2, t-1}}}\right), \\
& \operatorname{Pr}\left(Y_{t} \mid I_{t-1}\right)=\sum_{S_{1, t-1}=0}^{1} \sum_{S_{1, t}=0}^{1} \sum_{S_{2, t-1}=0}^{1} \sum_{S_{2, t}=0}^{1} \operatorname{Pr}\left(Y_{t}, S_{1, t-1}=i, S_{1, t}=j, S_{2, t-1}=i, S_{2, t}=j \mid I_{t-1}\right) \\
& \text { and } \\
& \operatorname{Pr}\left(S_{1, t-1}=i, S_{1, t}=j, S_{2, t-1}=i, S_{2, t}=j \mid I_{t-1}\right) \\
& =\operatorname{Pr}\left(S_{1, t}=j \mid S_{1, t-1}=i\right) \operatorname{Pr}\left(S_{2, t}=j \mid S_{2, t-1}=i\right) \operatorname{Pr}\left(S_{1, t-1}=i, S_{2, t-1}=i \mid I_{t-1}\right) \\
& \text { with } \\
& \operatorname{Pr}\left(S_{1, t-1}=i, S_{2, t-1}=i \mid I_{t-1}\right)=\sum_{S_{1, t-2}=0}^{1} \sum_{S_{2, t-2}=0}^{1} \operatorname{Pr}\left(S_{1, t-2}=i, S_{1, t-1}=i, S_{2, t-2}=i, S_{2, t-1}=i \mid I_{t-1}\right)
\end{aligned}
$$

At the end of each iteration, Equation 19 and Equation 20 are used to collapse 16 oneperiod posteriors $\left(X_{t \mid t}^{S_{1, t-1} S_{1, t} S_{2, t-1} S_{2, t}}\right.$ and $\left.P_{t \mid t}^{S_{1, t-1} S_{1, t} S_{2, t-1} S_{2, t}}\right)$ into $4\left(X_{t \mid t}^{S_{1, t} S_{2, t}}\right.$ and $\left.P_{t \mid t}^{S_{1, t} S_{2, t}}\right)$. As a by-product of the Hamilton filter, the approximate log likelihood function is given by 


$$
L(\theta)=\sum_{t=1}^{T} \ln f\left(Y_{t} \mid I_{t-1}\right)
$$

that will be maximized with respect to the parameter vector space $\Theta=\left\{p_{1,00}, p_{1,11}, p_{2,00}, p_{2,11}, \delta, k, a, \sigma_{1, H}, \sigma_{1, L}, \sigma_{2, H}, \sigma_{2, L}, \rho_{12}\right\}$. 


\section{New References}

Aussenegg, W., L. Götz, R. Jelic, 2014, European asset swap spreads and the credit crisis, European Journal of Finance, 17

\section{References}

Alexander, C., and A. Kaeck (2008), "Regime dependent determinants of credit default swap spreads," Journal of Banking and Finance 32, 1008-1021.

Ang, Andrew, and Monika Piazzesi, 2003, A no-arbitrage vector autoregression of term structure dynamics with macroeconomic and latent variables, Journal of Monetary Economics 50, 745-787.

Aunon-Nerin, D, D Cossin, T Hricko, and Z. Huang, 2002, Exploring for the determinants of credit risk in credit default swap transaction data: Is fixed-income markets information sufficient to evaluate credit risk?, HEC Working Paper.

Barclays Capital Research, Quantitative Credit Strategy, 2008. Cds curve trading handbook 2008.

Bedendo, Mascia, Lara Cathcart, and Lina El-Jahel, 2007, The slope of the term structure of credit spreads: An empirical investigation, Journal of Financial Research 30, 237257.

Berndt, A., and I. Obreja, (2010): "Decomposing European CDS Returns." Review of Finance 14 (2), 189-233.

Bhar, R., Colwell, D and Wong, P, (2008), Component Structure of Credit Default Swap Spreads and their Determinants, 21st Australasian Finance and Banking Conference 2008 Paper.

Blanco, Roberto, Brennan Simon, and Ian W. Marsh, 2005, An empirical analysis of the dynamic relation between investment-grade bonds and credit default swaps, The Journal of Finance 60, 2255-2281.

Byström, H., (2006), "CreditGrades and the iTraxx CDS Index Market," Financial Analysts Journal 62, 65-76.

Campbell, John Y., and Glen B. Taksler, 2003, Equity volatility and corporate bond yields, Journal of Finance 58, 2321-2349.

Clark, Peter K., 1987, The cyclical component of u. S. Economic activity, The Quarterly Journal of Economics 102, 797-814.

Collin-Dufresne P., R.S. Goldstein and J.S. Martin (2001): "The Determinants of Credit Spread Changes." Journal of Finance 56(6), 2177-2207.

Coopman S. and Ooms M., 2011, Forecasting Economic Time Series Using Unobserved Components Time Series Models. in: M.P. Clements and D.F. Hendry (eds), Oxford Handbook of Economic Forecasting, Oxford: Oxford University Press, Chapter 5, pp. 129-162.

Dieckmann, S. and T. Plank (2012): "Default Risk of Advanced Economies: An Empirical Analysis of Credit Default Swaps during the Financial Crisis." Review of Finance 16(4), 903-934.

Dionne, G., G. Gauthier, K. Hammamic, M. Maurice, J.-G. Simonato, 2011, A reduced form model of default spreads with Markov-switching macroeconomic factors, Journal of Banking and Finance, Vol. 35, pp. 1984-2000.

Engle, Robert, and Mark Watson, 1981, A one-factor multivariate time series model of metropolitan wage rates, Journal of the American Statistical Association 76, 774-781. 
Fama, Eugene F., and Kenneth R. French, 1988, Permanent and temporary components of stock prices, The Journal of Political Economy 96, 246-273.

Fender, I., Hayo, B., and Neuenkirch, M. (2012). Daily pricing of emerging market sovereign CDS before and during the global financial crisis. Journal of Banking and Finance, 36(10), 2786-2794.

Garcia, R, 1998, Asymptotic null distribution of the likelihood ratio test in markov switching models, International Economic Review 39, 763-788.

Giesecke, K., F.A. Longstaff, S. Schaefer, I. Strebulaev, 2011, Corporate bond default risk: A 150-year perspective, Journal of Financial Economics, Vol. 102, pp. 233-250.

Hamilton, James D, 1994, State space models, in Rober Engel, and Dan McFadden, eds.: Handbook of econometrics (Elsevier).

Hamilton, James D., 1989, A new approach to the economic analysis of nonstationary time series and the business cycle, Econometrica 57, 357-384.

Hansen, B. E., 1992, The likelihood ratio test under nonstandard conditions: Testing the markov switching model of gnp, Journal of Applied Econometrics 7, S61-S82.

Harvey, A. C., 1985, Trends and cycles in macroeconomic time series, Journal of Business \& Economic Statistics 3, 216-227.

Harvey, A. C., 1989. Forecasting structural time series models and the kalman filter (Cambridge University Press, Cambridge).

Harvey, A.C., and N. Shephard, 1993, Structural time series models, in et al. G.S. Maddala, ed.: Handbook of statistics (Elsevier Science Publisher).

Hull, John, Mirela Predescu, and Alan White, 2004, The relationship between credit default swap spreads, bond yields, and credit rating announcements, Journal of Banking \& Finance 28, 2789-2811.

Kim, Chang-Jin, 1994, Dynamic linear models with markov-switching, Journal of Econometrics 60, 1-22.

Kim, Chang-Jin, and Charles R. Nelson, 1989, The time-varying-parameter model for modeling changing conditional variance: The case of the lucas hypothesis, Journal of Business \& Economic Statistics 7, 433-440.

Kim, Chang-Jin, Jeremy M. Piger, and Richard Startz, 2007, The dynamic relationship between permanent and transitory components of u.S. Business cycles.

Kim, Don H., and Jonathan H. Wright, 2005, An arbitrage-free three-factor term structure model and the recent behavior of long-term yields and distant-horizon forward rates, (Board of Governors of the Federal Reserve System (U.S.)).

Kim, Myung Jig, Charles R. Nelson, and Richard Startz, 1991, Mean reversion in stock prices? A reappraisal of the empirical evidence, The Review of Economic Studies 58, 515-528.

Koop, G., M. H. Pesaran, and S. M. Potter, 1996, Impulse response analysis in nonlinear multivariate models, Journal of Econometrics 74, 119-147.

Lamoureux, Christopher G., and William D. Lastrapes, 1990, Persistence in variance, structural change, and the garch model, Journal of Business \& Economic Statistics 8, 225-234.

Lo, A. W., and A. C. MacKinlay, 1988, Stock market prices do not follow random walks: Evidence from a simple specification test, Review of Financial Studies 1, 41-66.

Lo, Andrew W., and A. Craig MacKinlay, 1990, Data-snooping biases in tests of financial asset pricing models, Review of Financial Studies 3, 431-467.

Longstaff, Francis A., Sanjay Mithal, and Eric Neis, 2005, Corporate yield spreads: Default risk or liquidity? New evidence from the credit default swap market, The Journal of Finance 60, 2213-2253. 
Longstaff, Francis A., and Eduardo S. Schwartz, 1995, A simple approach to valuing risky fixed and floating rate debt, Journal of Finance 50, 789-819.

Longstaff F. A., (2010), "The Subprime Credit Crisis and Contagion in Financial Markets", Journal of Financial Economics, No. 97, pp. 436-450.

Longstaff, F.A., J. Pan, L.H. Pedersen and K.J. Singleton (2011): "How Sovereign is Sovereign Credit Risk?" American Economic Journal: Macroeconomics 3(2), 75-103.

Merton, Robert C., 1974, On the pricing of corporate debt: The risk structure of interest rates, Journal of Finance 29, 449-470.

Morley, James, and Jeremy Piger, 2008, Trend/cycle decomposition of regime-switching processes, Journal of Econometrics 146, 220-226.

Nervole, M., D.M. Grether, and J.L. Carvalho, 1979. Analysis of economic time series: A synthesis (Academic Press, New York).

Pesaran, H. H., and Y. Shin, 1998, Generalized impulse response analysis in linear multivariate models, Economics Letters 58, 17-29.

Poterba, J. M., and L. H. Summers, 1988, Mean reversion in stock prices - evidence and implications, Journal of Financial Economics 22, 27-59.

Scheicher, M., 2009, The correlation of a firm's credit spread with its stock price: Evidence from credit default swaps, in G. N. Gregoriou, ed.: Stock market volatility (Chapman $\&$ Hall/CRC Finance Series).

Smith, J. M., and J. B. Taylor, 2009, The term structure of policy rules, Journal of Monetary Economics 56, 907-917.

Stock, J. H. and M. W. Watson (2007), Why Has U.S. Inflation Become Harder to Forecast?, Journal of Money, Credit and Banking 39, 3-33.

Summers, Lawrence H., 1986, Does the stock market rationally reflect fundamental values?, Journal of Finance 41, 591-601.

Taylor, John B., and John C. Williams, 2009, A black swan in the money market.

Watson, Mark W., 1986, Univariate detrending methods with stochastic trends, Journal of Monetary Economics 18, 49-75.

Zhu, Haibin, 2006, An empirical comparison of credit spreads between the bond market and the credit default swap market, Journal of Financial Services Research 29, 211-235. 